\title{
Gaseous VOCs rapidly modify particulate matter and its biological effects - Part 2: Complex urban VOCs and model PM
}

\author{
S. Ebersviller ${ }^{1}$, K . Lichtveld ${ }^{1}$, K. G. Sexton ${ }^{1}$, J. Zavala ${ }^{1}$, Y.-H. Lin ${ }^{1}$, I. Jaspers ${ }^{1,2}$, and H. E. Jeffries ${ }^{1}$ \\ ${ }^{1}$ Environmental Sciences and Engineering, Gillings School of Global Public Health, The University of North Carolina at \\ Chapel Hill, North Carolina, USA \\ ${ }^{2}$ Center for Environmental Medicine and Lung Biology, Human Studies Facility, The University of North Carolina at Chapel \\ Hill, North Carolina, USA
}

Correspondence to: S. Ebersviller (sebersviller@gmail.com)

Received: 13 January 2012 - Published in Atmos. Chem. Phys. Discuss.: 13 March 2012

Revised: 23 October 2012 - Accepted: 15 November 2012 - Published: 21 December 2012

\begin{abstract}
This is the second study in a three-part study designed to demonstrate dynamic entanglements among gaseous organic compounds (VOCs), particulate matter (PM), and their subsequent potential biological effects. We study these entanglements in increasingly complex VOC and PM mixtures in urban-like conditions in a large outdoor chamber, both in the dark and in sunlight. To the traditional chemical and physical characterizations of gas and PM, we added new measurements of gas-only- and PM-onlybiological effects, using cultured human lung cells as model living receptors. These biological effects are assessed here as increases in cellular damage or expressed irritation (i.e., cellular toxic effects) from cells exposed to chamber air relative to cells exposed to clean air. Our exposure systems permit side-by-side, gas-only- and PM-only-exposures from the same air stream containing both gases and PM in equilibria, i.e., there are no extractive operations prior to cell exposure for either gases or PM.

In Part 1 (Ebersviller et al., 2012a), we demonstrated the existence of PM "effect modification" (NAS, 2004) for the case of a single gas-phase toxicant and an inherently nontoxic PM (mineral oil aerosol, MOA). That is, in the presence of the single gas-phase toxicant in the dark, the initially non-toxic PM became toxic to lung cells in the PM-onlybiological exposure system. In this Part 2 study, we used sunlit-reactive systems to create a large variety of gas-phase toxicants from a complex mixture of oxides of nitrogen and 54 VOCs representative of those measured in US city air. In these mostly day-long experiments, we have designated the period in the dark just after injection (but before sun-
\end{abstract}

rise) as the "Fresh" condition and the period in the dark after sunset as the "Aged" condition. These two conditions were used to expose cells and to collect chemical characterization samples. We used the same inherently non-toxic PM from the Part 1 study as the target PM for "effect modification". Fortunately, in the absence of "seed particles", the complex highly-reactive VOC system used does not create any secondary aerosol in situ. All PM present in these tests were, therefore, introduced by injection of MOA to serve as PM-to-be-modified by the gaseous environment. PM addition was only done during dark periods, either before or after the daylight period. The purpose of this design is to test if a non-toxic PM becomes toxic in initially unreacted ("Fresh"), or in reacted ("Aged") complex VOC conditions. To have a complete design, we also tested the effects of clean air and the same VOC conditions, but without introducing any PM. Thus, there were six exposure treatment conditions that were evaluated with the side-by-side, gas-only- and PMonly-effects exposure systems; five separate chamber experiments were performed: two with clean air and three with the complex $\mathrm{VOC} / \mathrm{NO}_{\mathrm{x}}$ mixture.

For all of these experiments and exposures, chemical composition data and matching biological effects results for two end-points were compared. Chemical measurements demonstrate the temporal evolution of oxidized species, with a corresponding increase in toxicity observed from exposed cells. The largest increase in gas-phase toxicity was observed in the two "Aged" VOC exposures. The largest increase in particlephase toxicity was observed in the "Aged" VOC exposure with the addition of PM after sunset. These results are a 
clear demonstration that the findings from Part 1 can be extended to the complex urban oxidized environment. This further demonstrates that the atmosphere itself cannot be ignored as a source of toxic species when establishing the risks associated with exposure to PM. Because gases and PM are transported and deposited differently within the atmosphere and lungs, these results have significant consequences. In the next (and final) part of the study, testing is further applied to systems with real diesel exhaust, including primary PM from a vehicle operated with different types of diesel fuel.

\section{Introduction}

In its most-recent document summarizing the state of the science related to PM, the US National Research Council (NRC) stated that "a finding that the effect of particles depends on the concentration of another pollutant that is, "effect modification" would have implications for setting National Ambient Air Quality Standards (NAAQS) independently for the various criteria pollutants" (NAS, 2004).

In Part 1 (Ebersviller et al., 2012a), we demonstrated the existence of PM "effect modification" for the case of a single gas-phase toxicant and an inherently non-toxic PM (mineral oil aerosol, MOA). That is, in the presence of the single gasphase toxicant in the dark, the initially non-toxic PM became toxic to lung cells in the PM-only-biological exposure system. In the first experiment, the non-toxic PM (MOA) was added to clean air and both biological exposures were performed, which resulted in no response from cells to either gases or PM. In the second experiment, a gas-phase toxicant, either p-tolualdehyde or acrolein, was directly injected into clean air in the dark chamber and both biological effects exposures were performed. The result was an increase in response from the gas-only cells, but not the PM-only cells. In a third experiment both the gas-phase toxicant and the PM were added to the chamber, and both biological exposures were performed. In this case, the PM-only-exposures showed $2 \times$ to $4 \times$ larger responses than did the clean air exposures. The gas-only-exposures, in the PM-added experiment decreased significantly or remained about the same as the gas-only exposure in the absence of PM. That is, for the gas with lower volatility, it appears that much of the gasphase mass was removed to the PM, but in the higher volatility gas, it was less clear how the toxicant partitioned. These results showed that a gas from the environment surrounding an initially non-toxic PM could modify the PM so that it became toxic to lung cells due to atmospheric processes only. This is the "effect modification" that the NRC posed would have implications for research and regulation of PM.

This study was designed to extend our demonstration of the existence of "effect modification" to VOC systems that are more like those in large urban areas, but to have an exper- imental design simple enough to be relatively unambiguous about demonstrating the PM modification by the gas-phase.

Extensive literature exists regarding how gases and particles interact in important and dynamic processes during the ageing of anthropogenic emissions in the atmosphere. When PM is present, VOCs constantly shift between the gas and particle phases of ambient air, and at the same time they can be modified by chemical reactions in each phase. Partitioning theory that describes these processes has recently been coupled to atmospheric chemistry models in an attempt to capture and characterize these interactions in a quantitative way (Hu and Kamens, 2007; Donahue et al., 2006; Lee et al., 2004; Kamens and Jaoui, 2001; Pankow et al., 1997; Kamens et al., 1981). What has remained uncharacterised to this point is if - and how - these gas and particle interactions affect the actual toxicity of each phase.

Many toxicological studies focus on single species, or single primary pollutants, in the search for an entity that can be assigned causality for health outcomes observed in epidemiology studies (e.g., Steenhof et al., 2011; Farina et al., 2011; Schlesinger et al., 2006; Dreher, 2000). While it is useful to examine the effects of single pollutants, these studies ignore atmospheric ageing and the photochemical evolution of species that occurs during the day in the ambient environment. This simplified approach of ignoring secondary pollutants, while it permits laboratory studies to be undertaken, also ignores the complexity of the air we breathe in the ambient environment, and thereby misses the contribution of the atmosphere itself as a source of toxicity. "Such approaches are likely to over-simplify the underlying biological processes and how the mixture of air pollutants that is inhaled adversely affects health" (NAS, 2004).

The effects of photochemical-ageing and gas and particle interactions have recently begun to be evaluated for their impact on the relative risk associated with exposure (Doyle et al., 2004; Sexton et al., 2004; Doyle et al., 2007; Lichtveld et al., 2012). Previous experiments using outdoor irradiation chambers have measured significant changes in chemical composition as air pollution mixtures age in sunlight and, in most cases, have measured an accompanying increase in toxicity. In addition, these studies have indicated that the overall toxicity of an aged pollution mixture may not be completely accounted for by the major daughter products alone, and that significant portions of the observed response can be induced by exposure to minor, and even undetected, products (Sexton et al., 2004; Doyle et al., 2004, 2007).

Therefore, in designing this study, we used sunlit-reactive systems to create a large variety of gas-phase toxicants, including those not yet identified or detected, from a complex mixture of oxides of nitrogen (e.g., $\mathrm{NO}_{\mathrm{x}}, \mathrm{NO}$, and $\mathrm{NO}_{2}$ ) and 54 VOCs that serve as primary reactants in our outdoor sunlit chamber. The daylight reactions in this system consume a large portion of the primary VOCs and create a very large number of secondary oxidized products, with a wide distribution of life-times. Some of these products we cannot detect, 
and others we can detect but cannot identify explicitly. This would be a limitation if we were performing a toxicological dose-response study, but we are more interested in having a fully complex, urban-like system for exposure to living cells. For the purpose of these experiments, we are interested in the relative magnitude of cellular responses to reproducible, but not totally characterizable (at least within this study), systems to indicate the "types" of reactive systems that deserve further attention.

To maintain a system with little ambiguity for PM "effect modification" we used the same inherently non-toxic PM from the Part 1 study (Ebersviller et al., 2012a).

While we are aware of the dynamic interactions of gases and PM in an evolving photochemical oxidizing system with PM present, including these processes here would introduce ambiguity to our ability to interpret the effects results. Thus, in our experimental design, we exclude PM during the daytime photoactive period and only introduce it to test if the gases present will modify added non-toxic PM (causing the inherently non-toxic PM to become toxic to cells). This would clearly be "effect modification" as posed by the NAS. Our primary hypothesis is that - because many urban atmospheres are capable of acting as a source of toxicity via the creation of photochemically-aged daughter species in situ - non-toxic PM, in the presence of a photochemically-aged urban-like mixture, will become toxic to lung cells via the uptake of the toxic gases present in the aged mixture.

\section{Methods}

The methods and procedures used in this Part 2 study were essentially identical to those reported in the Part 1 study (Ebersviller et al., 2012a). Thus, only brief summaries of these will be given here.

\subsection{Chamber}

The experiments described here were performed in the Gillings Innovation Laboratory $120 \mathrm{~m}^{3}$ chamber on the roof of the four story School of Global Public Health at UNC, the same as used in the Part 1 study (Fig. 1). The chamber is above all surrounding buildings and receives direct sunshine on its tilted Teflon film faces.

The chemical and biological analysis laboratories are located directly below the roof-top chamber on the fourth floor. Pollutants to be studied (VOCs, PM, etc.) are injected into the chamber through its floor. Chamber contents are monitored continuously via sample lines that pass through the floor of the chamber, the roof of the building, and into the laboratory below. These same sample lines provide chamber air to the biological effects exposure systems that are maintained in an incubator with proper conditions to support living humanderived lung cells. For analytes that may be lost in long trans-

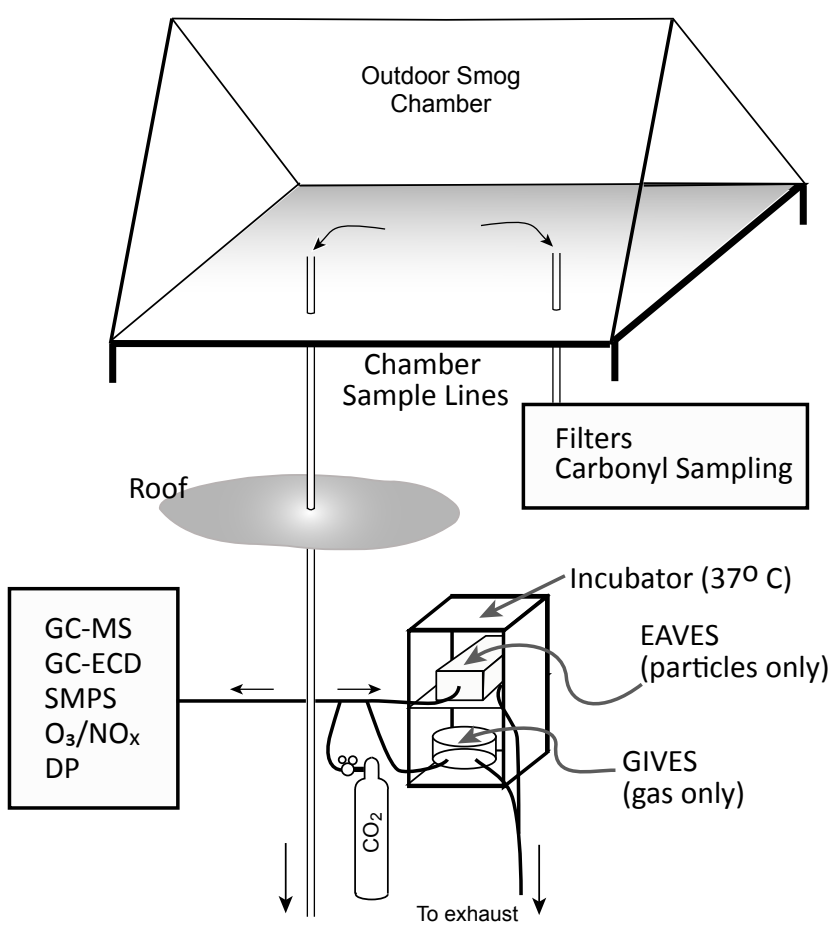

Fig. 1. Schematic of The Gillings Innovation Laboratory $120 \mathrm{~m}^{3}$ Outdoor Chamber located on the roof of the four-story Gillings School of Global Public Health, UNC-CH. Sample lines pass through the floor of the chamber, the building's roof, and then directly into the chemistry and biological exposure laboratory on the fourth floor. Filter and carbonyl-specific sampling are performed on the roof directly through the chamber floor to minimize loss in sample lines.

fer lines, samples are collected directly below the chamber on the roof of the building.

\subsection{Gas phase compositional analysis}

\subsubsection{Direct sampling of the chamber by gas chromatography}

Chamber air was sampled directly with a Varian 3400 gas chromatograph with flame ionization detector (FID) and coupled to a Saturn 2000 mass spectrometer (GC-MS). The dilution rate of the chamber was monitored continuously by a Varian $3800 \mathrm{GC}$ with an electron capture detector (ECD). A Varian 3800 GC with Saturn 2200 mass spectrometer (MS) was used to analyse condensed-phase samples (such as function-specific or filter samples). See (Ebersviller et al., 2012a) for more details on components and operating conditions for these systems.

\subsubsection{Species-specific analysis of carbonyls}

Our chemical analysis places a large focus on carbonylcontaining compounds because they are the major oxidation 
products of primary VOCs, and from earlier research have been shown to have great influence on the toxicity of an aged air mass (Takigawa et al., 2009; Hauptmann et al., 2004; Zhang and Smith, 2003; WHO, 2000). In this study, selective ion analysis for carbonyl-containing compounds was performed with o-(2,3,4,5,6-pentafluorobenzyl) hydroxylamine chloride (PFBHA) as described before (Ebersviller et al., 2012a). Mixtures of gases and particles were sampled with midget impinger apparatuses similar to those described before (Yu et al., 1995, 1997; Liu et al., 1999b,a). While we could visually see that some PM was collected in the impinger, we acknowledge that the impingers' collection efficiencies are difficult to accurately quantify for PM. As such, we can be certain that some of the PM in the mixture was collected, but we cannot determine unambiguously the percentage collected. The PFBHA-derivatised measurements should, therefore, be thought to represent an indication of the species present in the mixture, but not absolute quantification of the total production of a given species by the system. Impinger samples were collected at $1 \mathrm{~L} \mathrm{~min}^{-1}$ for ca. $3 \mathrm{~h}$.

\subsubsection{Inorganic gas phase analysis/chamber condition monitoring}

Ozone $\left(\mathrm{O}_{3}\right)$ and nitrogen oxides $\left(\mathrm{NO}_{\mathrm{x}}\right)$ concentrations in the chamber were monitored continuously (ML9811 Ozone Photometer and ML9841 $\mathrm{NO}_{\mathrm{x}}$ Oxides of Nitrogen Analyzer, Monitor Labs, Englewood, CO), as were chamber temperature and dew point (DP). These chamber data were recorded with one-minute resolution using a data acquisition system connected to a computer. Prior to each experiment, the $\mathrm{O}_{3}$ and $\mathrm{NO}_{\mathrm{x}}$ meters were calibrated by gas-phase titration using a NIST standard $\mathrm{NO}$ tank and stable $\mathrm{O}_{3}$ source.

\subsection{Particle phase analysis}

\subsubsection{Scanning mobility particle sizer}

During all experiments, the size distribution and mass concentration of the aerosols in the test atmospheres were monitored with a Scanning Mobility Particle Sizer (SMPS; TSI Inc., St. Paul, MN). All particle-phase analyses were performed as described in the Part 1 study.

\subsubsection{Teflon membrane filters}

Teflon membrane filters $(2 \mu \mathrm{m}$ pore size, $47 \mathrm{~mm}$ diameter: Pall Corporation, New York) were used to collect particles at an average flow rate of $17.5 \mathrm{~L} \mathrm{~min}^{-1}$ for $3 \mathrm{~h}$. Filters were collected concurrently with exposure periods. The aerosol mass concentration in the air was calculated by dividing the mass collected on the filter by the total volume of air sampled during collection. This value was used as a check against the value calculated from SMPS data. All particle-phase analyses were performed as described in the Part 1 study.

\subsection{Biological effects model and measurements of response}

Cultured human epithelial lung cells, type A549, were used as the biological receptor model in this study. A549 human respiratory cells are a commercially available cell line that have been shown to react in a manner that is representative of the human airway in vivo (Lieber et al., 1976; ATCC, 2011). The A549 cells were cultured and prepared for exposure as explained previously (Jaspers et al., 1997; Doyle et al., 2004; Sexton et al., 2004; de Bruijne et al., 2009; Ebersviller et al., 2012a).

The Gas In Vitro Exposure System (GIVES) and Electrostatic Aerosol in Vitro Exposure System (EAVES) have also been described in detail previously (Ebersviller et al., 2012a; Lichtveld et al., 2012; de Bruijne et al., 2009; Doyle et al., 2004, 2007; Sexton et al., 2004). Briefly, these systems allow the cellular toxicity of the gaseous and particle phase components of the same air pollution mixture to be evaluated independently of one another, and with no substantive modification to the sample prior to exposure. This allows cells to encounter pollutants as they might in the ambient environment. These exposure systems are not an attempt to reproduce a human deep lung in all of its complexity. They are models intended to be biosensors - a means by which to further characterize the distribution of species among the gas and particle phases, and to indicate which systems warrant further evaluation for harmful biological effects. This is measured by gauging cellular responses to treatment air exposures relative to clean air exposures. Gas-only exposures in GIVES lasted $4 \mathrm{~h}$ in all experiments. PM-only exposures in EAVES lasted $30 \mathrm{~min}$. Post-exposure treatment and processing were performed as described before (Ebersviller et al., 2012a).

\subsubsection{Biological effects endpoints (cytotoxicity and inflammation)}

Cytotoxicity is expressed as the increase of lactate dehydrogenase (LDH) levels over clean air controls, as outlined before (Ebersviller et al., 2012a). LDH levels were measured using a Cytotoxicity Detection Kit (TaKaRa Bio Inc., Tokyo, Japan). Interleukin 8 (IL-8) cytokine release was evaluated using an ELISA kit (BD Biosciences, San Diego, CA). Inflammatory response is reported as the increase of IL-8 levels over clean air controls.

Bar plots of treatment response measurements over control response measurements are produced as data results. These values are then used to compare exposure results of one treatment with another treatment. The latter are presented as tables of relative response ratios. Further description of these calculations can be found in Part 1 (Ebersviller et al., 2012a). 


\subsection{Statistical analysis}

All calibration curves were tested by fitting a linear least squares line through the data. Calibration factors were calculated for each species to be analysed, with appropriate propagation of uncertainty. All instrument measurements are reported as the mean $\pm 95 \%$ confidence interval, unless otherwise stated. The statistical analyses of toxicity endpoints were the same as those used in Part 1 study (Ebersviller et al., 2012a).

\subsection{Experimental design}

\subsubsection{Urban VOC mixture and non-toxic PM}

The VOC mixture used in Part 2 experiments was based on canister samples of 06:00-09:00 a.m. ambient air collected and analysed by the US EPA in 39 large cities in the US (Seila et al., 1989). UNC researchers previously analysed this database to create a 200 species average VOC composition of urban air (Jeffries, 1995). From this analysis, UNC researchers also created a synthetic VOC mixture (consisting of 54 VOC species) that was closely based on the EPA analysis of more than 1000 canisters. This mixture was created to facilitate accurate and reproducible initial injections of urban-like primary VOC emissions into the UNC chambers (Jeffries et al., 1985). In the design of this synthetic VOC mixture, care was taken to choose a composition that had more than $70 \%$ of the carbon represented explicitly in the mix and to choose the other components to match the average carbon fractions, average carbon number, and branching ratios in each of the VOC groupings (alkanes, alkenes, aromatics, and carbonyls). The lighter compounds of the synthetic mixture were produced as a commercially-certified gas cylinder, with $10000 \mathrm{ppmC}$ of the VOCs mixed in nitrogen. The heavier species were blended as a mixture of liquid hydrocarbons. The result is that only two simple injections into the chamber are required to achieve a highly reproducible total distribution of VOCs. A very large number of chamber experiments have been conducted with this mix - called Synthetic Urban Mixture - and it has also been used in chamber experiments around the world (Simonaitis et al., 1997; Johnson et al., 1997).

In the absence of "seed aerosol", this complex and highlyreactive system does not create any secondary aerosol in situ. Thus, its use will not create any secondary PM (with perhaps inherent toxicity) into the observation of the PM effects. This experimental design for the atmospheric chemistry environment results in a complex and highly realistic, but not totally quantifiable, set of gas-phase potential toxicants that are available for both gas-only exposures, and for potential uptake by test PM we introduce to the chamber to test PM "effect modification." The composition of Synthetic Urban Mixture (SynUrb54) is given in Table 1. In this Part 2 study, SynUrb54 and $\mathrm{NO}_{\mathrm{x}}$ were used to represent a "typi- cally reactive" gas-only urban environment (i.e., no primary PM). In three Part 2 experiments, SynUrb54 was injected into the chamber in the dark to a total carbon mixing ratio of $2.00 \mathrm{ppmC}$ with ca. $0.30 \mathrm{ppm}$ of $\mathrm{NO}_{\mathrm{x}}$ (Table 3).

To maintain a system with little ambiguity for PM "effect modification," we used the same inherently non-toxic PM from the Part 1 study (Ebersviller et al., 2012a). This PM was created by nebulising steri-filtered liquid mineral oil (pharmaceutical grade, $100 \%$ ) into the chamber, thereby creating mineral oil aerosol (MOA). For this study, MOA is a convenient and sufficiently complex surrogate for ambient PM that contains organic material, as described in Part 1. The addition of PM to the chamber during experiments was only done in the dark (either before sunrise or after sunset), to be present during the biological-effects sampling. No experiment had a daylight period in which PM was present.

\subsubsection{Chamber conditions and example data}

In Part 2 we simulate the complexity of the ambient atmosphere by performing both day-long photochemical experiments (to produce significant oxidation conditions in our outdoor chamber), and shorter night-time experiments (for "blanks" or "thermal-only" conditions). The photochemical experiments start in the dark with realistic mixtures of urban hydrocarbons (i.e., SynUrb54) and $\mathrm{NO}_{\mathrm{x}}$ that undergo oxidation in ambient sunlight. After sunset, chamber contents are retained into the dark period to permit additional sampling and exposures. The experimental operation can be better understood by examining Tables 2 and 3 and an example experiment shown in Figs. 2, 3, and 4.

In Table 2, the chamber experiments are given both an Experiment Number, which is a Roman numeral, I to $\mathrm{V}$, and a run date-derived name, e.g. "JN2509". The biological exposure tests periods are given Exposure Labels, which are upper-case letters, A to F ("Expo. Label" in Table 2). More details of the conditions of the biological exposures are given in Table 3 using the same Exposure Labels.

Table 2 shows that there were two "Clean Air" dark experiments, two SynUrb54/NO $\mathrm{N}_{\mathrm{x}}$ sunlit experiments, and one SynUrb54/NO ${ }_{x}$ dark (i.e., "Fresh with MOA") experiment. Of the five chamber experiments, three had MOA added in the dark. One sunlit experiment (Expt. III) had no MOA added in either "Fresh" or "Aged" periods (Expo. C and E). This was to produce gas-only "Fresh" and gas-only "Aged" exposures for contrast to the "Fresh" (Expt. IV, Expo. D) and "Aged" exposures (Expt. V, Expo. F) with added-PM.

To illustrate the relation among the chemical conditions and the biological exposures during the sunlit experiments, the time series data for several inorganic and organic species for one experiment (Expt. III) are shown in Figs. 2, 3, and 4. On each figure, shading is used to indicate "dark" periods, and the actual time for sunrise and sunset are marked at the top of each plot. VOCs and $\mathrm{NO}_{\mathrm{x}}$ were injected at 02:30 EDT for this experiment. In these experiments, we have designated 


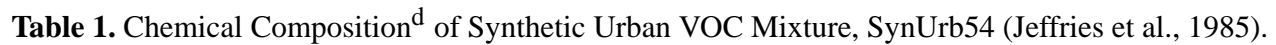

\begin{tabular}{|c|c|c|c|c|c|}
\hline Alkanes & $\mathrm{ppbC}^{\mathrm{a}}$ & Alkenes & $\mathrm{ppbC}^{\mathrm{b}}$ & Aromatics & $\mathrm{ppbC}^{\mathrm{c}}$ \\
\hline isopentane & 86.4 & ethene & 26.7 & toluene & 69.0 \\
\hline n-butane & 73.5 & 2,3,3-trimethyl-1-butene & 16.0 & 1,2,4-trimethylbenzene & 56.0 \\
\hline propane & 46.1 & c-2-pentene & 13.5 & m-xylene & 37.0 \\
\hline ethane & 38.5 & $\mathrm{t}$-2-butene & 11.6 & benzene & 22.0 \\
\hline 3-methylhexane & 35.0 & propene & 8.4 & 1,3-diethylbenzene & 18.0 \\
\hline isobutane & 32.9 & 1-octene & 8.0 & o-xylene & 16.0 \\
\hline n-pentane & 31.1 & 2-methyl-1-pentene & 8.0 & p-ethyltoluene & 15.0 \\
\hline 4-methylnonane & 23.0 & 1-pentene & 8.0 & ethylbenzene & 11.0 \\
\hline 2-methylpentane & 22.0 & 1-nonene & 7.0 & n-propalbenzene & 11.0 \\
\hline n-decane & 20.0 & 2-methylpropene & 4.5 & m-ethyltoluene & 10.0 \\
\hline 2,3-dimethylpentane & 17.0 & 2-methyl-1-butene & 4.2 & sec-butylbenzene & 7.0 \\
\hline n-nonane & 16.0 & 2-methyl-2-pentene & 3.0 & 1,2,3,5-tetramethylbenzene & 6.0 \\
\hline n-heptane & 16.0 & cyclohexene & 1.0 & & \\
\hline 3-methylpentane & 16.0 & & & & \\
\hline n-hexane & 14.0 & Dialkenes & $\mathrm{ppbC}$ & Alkenated Aromatics & $\mathrm{ppbC}$ \\
\hline 2,2,4-trimethylpentane & 13.0 & 1,3-butadiene & 2.1 & $\alpha$-methylstyrene & 3.0 \\
\hline n-octane & 12.0 & isoprene & 3.0 & & \\
\hline 2,5-dimethylhexane & 11.0 & $\alpha$-pinene & 6.0 & & \\
\hline 2,3,4-trimethylhexane & 10.0 & & & Aldehydes & $\mathrm{ppbC}$ \\
\hline 2,3-dimethylbutane & 6.0 & & & formaldehyde & 10.4 \\
\hline methylcyclopentane & 11.0 & & & acetaldehyde & 11.2 \\
\hline cyclohexane & 10.0 & & & & \\
\hline methylcyclohexane & 6.0 & & & & \\
\hline
\end{tabular}

the period in the dark just after injection (but before sunrise) as the "Fresh" condition and the period in the dark after sunset as the "Aged" condition. These two time-windows were used to expose cells and to collect additional chemical characterization samples. The exposures and chemical characterization samples were performed in the dark to ensure that any chemical reactions occurring in the system were proceeding slowly and that substantial modification of the chamber contents would not occur during the sampling windows. On these time-series plots, biological exposure windows are designated by orange bars. The gas-only exposures occurred during the times marked by the solid bars, and the PM-only exposures occurred during the shorter bars with alternating orange and black bands. Additional sampling to characterize the chemical environment during the "Fresh" and "Aged" conditions are designated by the magenta bar and the blue dashed bar. Individual GCMS sampling times are designated by red circles.

During the particular experiment illustrated (Expt. III, performed on JN2509), no PM was added at any point. For experiments in which PM was added (see Table 2), it was injected at the beginning of the "Fresh" window or at the be- ginning of the "Aged" window to permit the gases present to modify the inherently non-toxic PM. Of course, if PM was added to the "Fresh" window, the subsequent day time oxidation would be affected due to both evaporation of MOA mass to the gas phase, and perhaps due to gain in PM mass from secondary organic aerosol production on the MOA surface. In this case (Expt. IV, performed on ST2310), the experiment was used only for "Fresh with MOA" exposure (Expo. D), and the rest of the experiment was discarded. A separate whole-day experiment (Expt. V, performed on ST1510) was performed to produce an "Aged with MOA" exposure (Expo. F) in which the PM was added only after sunset to the otherwise gas-only mixture.

\subsubsection{Summary: conditions and exposure strategy}

Within these SynUrb54 experiments we used the "Fresh" and "Aged" time-windows to either sample the gas system without PM, or to add MOA to the gas system and sample. This created four different complex gas and PM measurement and exposure conditions. To these four conditions we added two clean air control conditions, resulting in six comparison conditions necessary to demonstrate the existence of 


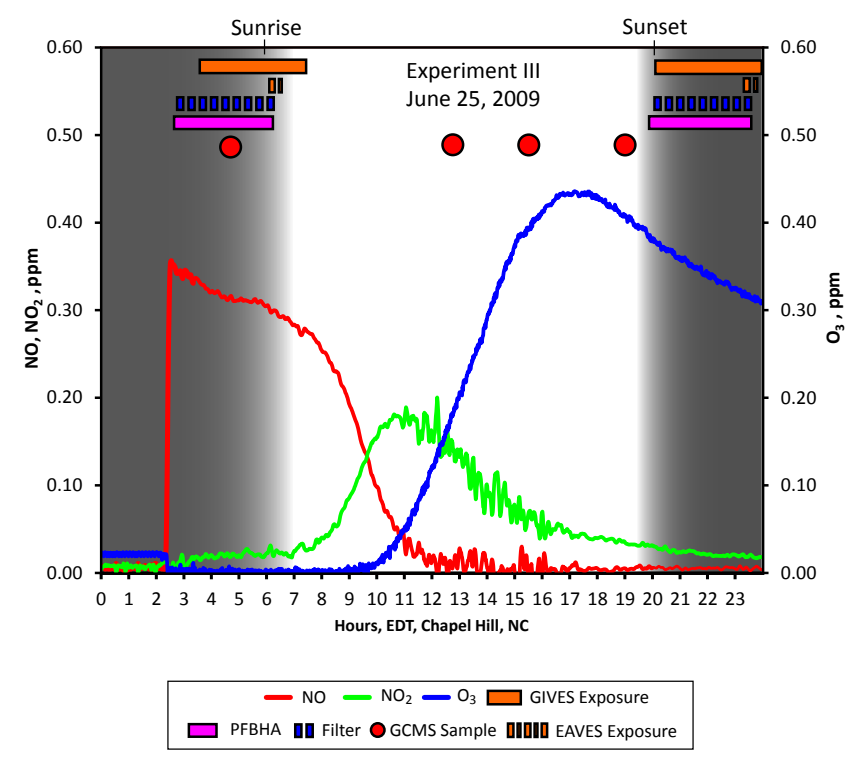

Fig. 2. Time series of ozone $\left(\mathrm{O}_{3}\right)$, nitric oxide (NO), and nitrogen dioxide $\left(\mathrm{NO}_{2}\right)$ during experiment III (JN2509), performed with SynUrb54 and $\mathrm{NO}_{\mathrm{x}}$ injected in the dark at 02:30 EDT. Color bars represent the type and time window for biological exposure sampling (GIVES, EAVES), for filter sampling, and for impinger sampling for PFBHA carbonyl analysis; red dots represent the time of VOC sampling for GCMS direct injection analyses.

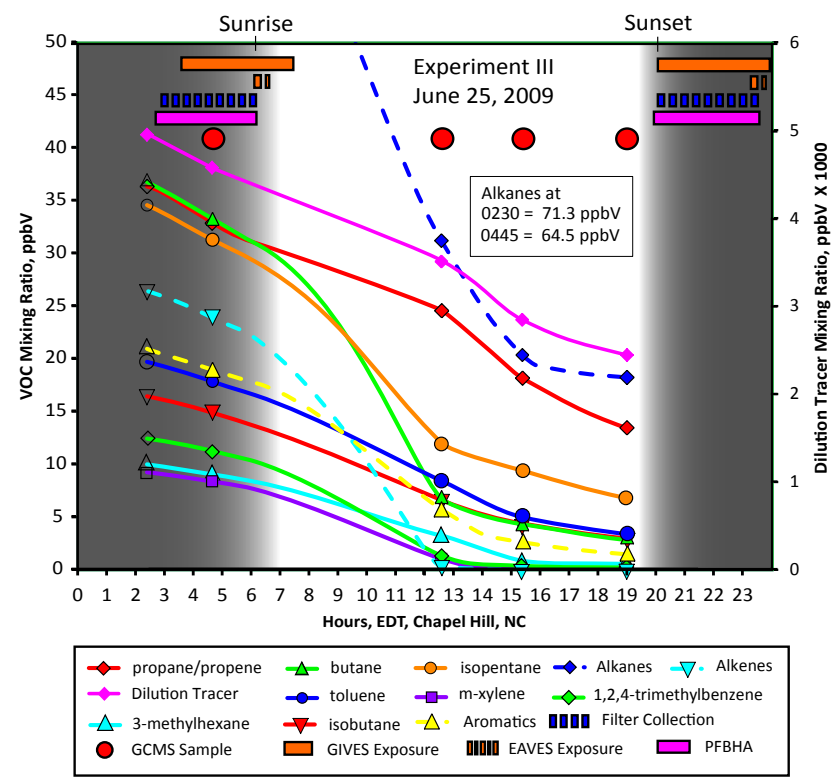

Fig. 3. Time series of explicit (solid lines) or functionally-grouped (dashed lines) primary (injected) VOC mixing ratios during experiment III (JN2509), performed with SynUrb54 and $\mathrm{NO}_{\mathrm{x}}$ injected in the dark at 02:30 EDT. Explicitly represented species are not included in their functional group mixing ratio values. Colored bars and large red dots are as in Fig. 2. See Table 4 for mixing ratio values at specific time points.

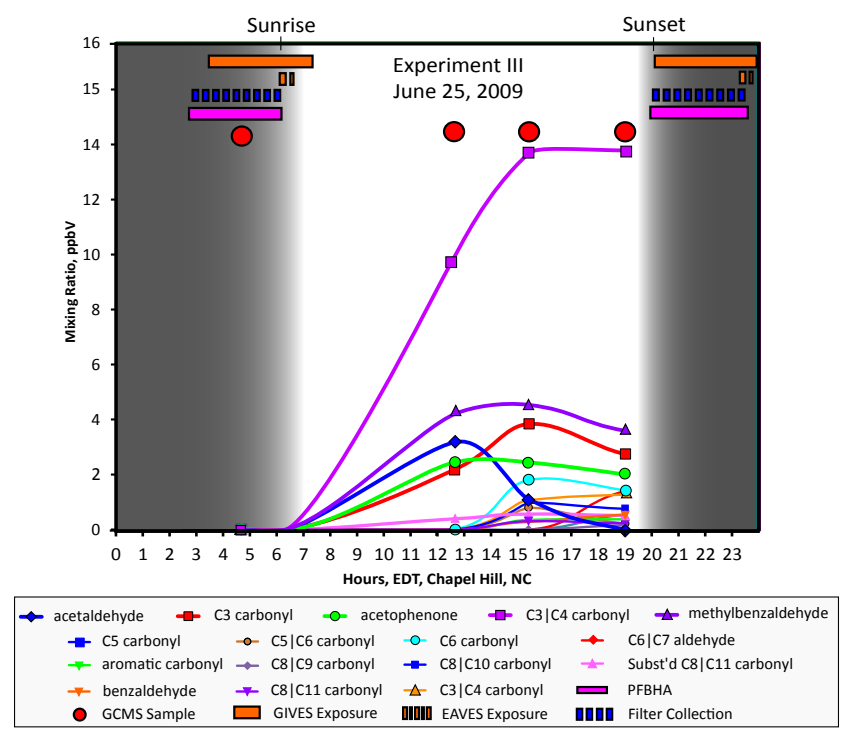

Fig. 4. Time series of explicit or type-identified, secondary VOCs produced during experiment III (JN2509), performed with SynUrb54 and $\mathrm{NO}_{\mathrm{x}}$ injected in the dark at 02:30EDT. The symbol between carbon number names means "or"; the functionality is specified if known, the carbon chain length is estimated by retention times. Colored bars and large red dots are as in Fig. 2. See Table 4 for mixing ratio values at specific time points.

PM "effect modification" for complex, urban-like gaseous environments. Because of the need for both initial and final VOC conditions tested with and without PM, five different experiments were necessary to generate these six chamber conditions (Expo. A-F; summarized in Table 3). As stated above, all biological exposures for gas-only- and PM-onlyeffects occurred during "Fresh" or "Aged" conditions, in the dark, either before sunrise or after sunset.

\section{Results}

The results are organized into sections related to:

1. the temporal changes in the gas-phase $\mathrm{NO}_{\mathrm{x}}, \mathrm{O}_{3}$, and VOC concentrations as revealed by the gas monitors, the GCMS, and FID measurements;

2. the temporal creation of secondary carbonyl species, some of which were further oxidized, as revealed by direct GCMS sampling and GCMS of PFBHA-derivatised samples;

3. the demonstration of a lack of secondary PM formation from the daytime oxidation of the SynUrb54 VOCs (as revealed by SMPS measurements); the quantification of MOA size distributions and mass concentrations following the injection of MOA into the chamber during dark periods (before and after the oxidation experiments, as revealed by SMPS and filter sample measurements); 
Table 2. Chamber Experimental Runs and Relevant Conditions.

\begin{tabular}{|c|c|c|c|c|c|c|c|c|c|c|}
\hline \multirow[b]{3}{*}{ Expt. } & \multicolumn{2}{|c|}{ Identification } & \multicolumn{5}{|c|}{ Experimental Conditions } & \multirow{2}{*}{\multicolumn{3}{|c|}{$\begin{array}{l}\text { Biological Exposure } \\
\text { Expo. Label }^{\mathrm{b}}\end{array}$}} \\
\hline & & & \multirow[b]{2}{*}{$\begin{array}{l}\text { Solar } \\
\text { Exposure }\end{array}$} & \multicolumn{2}{|c|}{ Initial Conc. } & \multicolumn{2}{|c|}{ Added $\mathrm{MOA}^{\mathrm{a}}$} & & & \\
\hline & Name & Type & & $\begin{array}{l}\text { VOC } \\
\text { ppmC }\end{array}$ & $\begin{array}{l}\mathrm{NO}_{\mathrm{x}} \\
\mathrm{ppm}\end{array}$ & $\begin{array}{l}\text { Fresh } \\
\mathrm{mg} \mathrm{m}^{-3}\end{array}$ & $\begin{array}{l}\text { Aged } \\
\mathrm{mg} \mathrm{m}^{-3}\end{array}$ & Fresh & Aged & Note \\
\hline I. & AP2808 & Clean Air & Dark & 0.00 & 0.00 & - & - & A. & - & 1 \\
\hline II. & AU1909 & $\begin{array}{l}\text { Clean Air, w/ } \\
\text { MOA }\end{array}$ & Dark & 0.00 & 0.00 & 1.56 & - & B. & - & 2 \\
\hline III. & JN2509 & $\begin{array}{l}\text { SynUrb54, } \\
\text { Gas only }\end{array}$ & $\begin{array}{l}\text { Sunlit } \\
(14 \mathrm{~h})\end{array}$ & 2.00 & 0.30 & - & - & C. & E. & 3 \\
\hline IV. & ST2310 & $\begin{array}{l}\text { Fresh } \\
\text { SynUrb54, w/ } \\
\text { MOA }\end{array}$ & Dark & 2.00 & 0.30 & 0.90 & - & D. & - & 4 \\
\hline V. & ST1510 & $\begin{array}{l}\text { Aged } \\
\text { SynUrb54, w/ } \\
\text { MOA }\end{array}$ & $\begin{array}{l}\text { Sunlit } \\
(12 \mathrm{~h})\end{array}$ & 2.00 & 0.30 & - & 0.89 & - & F. & 5 \\
\hline
\end{tabular}

\footnotetext{
a Mineral Oil Aerosol.

b See Table 3 for biological exposure condition details.

Notes:

1. used in Figs. 10, 11; Tables 3, 7,

2. used in Figs. 8, 10, 11; Tables 3, 7

3. used in Figs. 2, 5, 3, 4, 6, 10, 11; Tables 4, 5, 6, 3, 7

4. used in Figs. 8, 10, 11; Tables 5, 3, 7

5. used in Figs. 8, 7, 10, 11; Tables 5, 6, 3, 7.
}

Table 3. Six Exposure Conditions During Blank and Complex Mixture Experiments.

\begin{tabular}{|c|c|c|c|c|c|c|c|c|c|c|}
\hline \multirow[b]{2}{*}{ Expo. $^{\mathrm{a}}$} & \multicolumn{3}{|c|}{ Treatment } & \multicolumn{4}{|c|}{ Mixing Ratio } & \multirow{2}{*}{$\begin{array}{c}\text { Concentration } \\
\qquad \begin{array}{c}\mathrm{PM} \\
\mathrm{mg} \mathrm{m}^{-3}\end{array}\end{array}$} & \multicolumn{2}{|c|}{ Relative Humidity } \\
\hline & State $^{b}$ & VOC/NO ${ }_{x}$ Mix & $\begin{array}{l}\text { MOA }^{\mathrm{c}} \\
\text { added }\end{array}$ & $\begin{array}{l}\text { VOC } \\
\text { ppmC }\end{array}$ & $\begin{array}{l}\text { Ozone } \\
\text { ppm }\end{array}$ & $\begin{array}{l}\text { NO } \\
\text { ppm }\end{array}$ & $\begin{array}{l}\mathrm{NO}_{\mathrm{x}} \\
\mathrm{ppm}\end{array}$ & & $\begin{array}{c}\% \\
\text { In Chamber }\end{array}$ & $\begin{array}{c}\% \\
\text { In Exposure }\end{array}$ \\
\hline A. & Clean & none & & $\mathrm{ND}^{\mathrm{d}}$ & 0.009 & 0.007 & 0.008 & 0.001 & 47.8 & 31.7 \\
\hline B. & Clean & none & MOA & $\mathrm{ND}^{\mathrm{d}}$ & 0.009 & 0.007 & 0.007 & 1.562 & 69.2 & 30.1 \\
\hline C. & Fresh & SynUrb54/NO ${ }_{\mathrm{x}}$ & & 1.80 & 0.002 & 0.231 & 0.304 & 0.001 & 74.6 & 29.9 \\
\hline D. & Fresh & SynUrb54/NO ${ }_{\mathrm{x}}$ & MOA & 1.80 & 0.003 & 0.232 & 0.312 & 0.898 & 61.1 & 38.9 \\
\hline E. & Aged & SynUrb54/NO ${ }_{\mathrm{x}}$ & & 0.86 & 0.344 & 0.001 & 0.085 & 0.001 & 35.4 & 29.6 \\
\hline F. & Aged & SynUrb54/NO & MOA & 1.07 & 0.459 & 0.002 & 0.052 & 0.867 & 55.2 & 31.0 \\
\hline
\end{tabular}

${ }^{\text {a }}$ Exposure Label. All exposures occur in dark before (Clean, Fresh) or after (Aged) daylight period.

b Chamber state during exposure. Fresh is injected $\mathrm{VOC} / \mathrm{NO}_{\mathrm{x}}$ mixture in dark; Aged is dark period after daytime reaction period.

${ }^{c}$ MOA is mineral oil aerosol added only in dark for exposures $\mathrm{B}, \mathrm{D}$, and F. MOA was not present during photo-irradiation.

d None detected.

All measurements represent the mean value over an entire exposure interval.

4. the consistency of the organic and inorganic gas-phase conditions and the PM concentrations in each of the six biological exposures as revealed by matching data across experiments;

5. the graphical and tabular biological relative responses for the two biological endpoints, inflammation and cellular damage, for the six exposure conditions as revealed by the biological assays of the cellular media.

Each of these datasets will be briefly highlighted and the location of selected results will be cited in figures and tables.

\subsection{Primary $\mathrm{NO}_{\mathrm{x}}$ and VOC oxidation and dilution loss results}

Time-series plots from an example experiment for the consumption of NO and VOCs, as well as the resulting production of $\mathrm{O}_{3}$ and multiple generations of oxidized daughter compounds are shown in Figs. 2-4. The species included in Fig. 3 are limited to those found in SynUrb54 (Table 1), with specific, major components represented explicitly and others grouped by organic function. Species represented explicitly 
Table 4. GCMS Measured VOC species at four times during experiment III (JN2509) using SynUrb54/NO in Gillings Outdoor Chamber. See Fig. 5 for the corresponding chromatograms.

\begin{tabular}{|c|c|c|c|c|c|c|c|c|c|c|c|}
\hline \multirow[b]{2}{*}{ Id. } & \multirow[b]{2}{*}{ Species } & \multicolumn{4}{|c|}{ Mixing ratio, ppbV; Time, EDT } & \multirow[b]{2}{*}{ Id. } & \multirow[b]{2}{*}{ Species } & \multicolumn{4}{|c|}{ Mixing ratio, ppbV; Time, EDT } \\
\hline & & $04: 45$ & $12: 44$ & $15: 25$ & 19:00 & & & 04:45 & $12: 44$ & $15: 25$ & 19:00 \\
\hline 1 & propane/propene & 36.33 & 24.61 & 18.15 & 13.46 & 30 & $\mathrm{C} 8 \mid \mathrm{C} 9$ carbonyl & 0.00 & 0.00 & 0.00 & 0.17 \\
\hline 2 & isobutane & 16.45 & 6.62 & 4.40 & 2.98 & 31 & $\mathrm{C} 8 \mid \mathrm{C} 10$ carbonyl & 0.00 & 0.00 & 0.98 & 0.77 \\
\hline 3 & acetaldehyde & 0.00 & 3.24 & 1.13 & 0.00 & 32 & methylcyclohexane & 1.71 & 0.57 & 0.29 & 0.14 \\
\hline 4 & butane & 36.75 & 6.74 & 4.33 & 2.84 & 33 & 2,5-dimethylhexane & 2.75 & 0.16 & 0.57 & 0.37 \\
\hline 5 & C3 carbonyl & 0.00 & 2.23 & 3.91 & 2.80 & 34 & 2,3,4-trimethylhexane & 2.22 & 0.85 & 0.57 & 0.32 \\
\hline 6 & $\mathrm{C} 3 \mid \mathrm{C} 4$ carbonyl & 0.00 & 0.00 & 1.09 & 1.30 & 35 & toluene & 19.71 & 8.44 & 4.99 & 3.37 \\
\hline 7 & isopentane & 34.56 & 11.70 & 9.64 & 6.78 & 36 & 1-octene & 2.00 & 0.00 & 0.00 & 0.00 \\
\hline 8 & $\mathrm{C} 3 \mid \mathrm{C} 4$ carbonyl & 0.00 & 9.51 & 13.93 & 14.03 & 37 & n-octane & 3.00 & 1.28 & 0.93 & 0.29 \\
\hline 9 & 1-pentene & 3.20 & 0.00 & 0.00 & 0.00 & 38 & Subst'd C8|C11 carbonyl & 0.00 & 0.40 & 0.57 & 0.52 \\
\hline 10 & n-pentane & 12.44 & 1.77 & 0.84 & 0.45 & 39 & ethylbenzene & 2.75 & 1.23 & 0.78 & 0.48 \\
\hline 11 & trans-2-butene & 5.80 & 0.00 & 0.00 & 0.00 & 40 & m-xylene & 9.25 & 1.05 & 0.23 & 0.06 \\
\hline 12 & cis-2-pentene & 5.40 & 0.32 & 0.00 & 0.00 & 41 & o-xylene & 4.00 & 1.04 & 0.50 & 0.23 \\
\hline 13 & C5 carbonyl & 0.00 & 0.00 & 0.00 & 0.56 & 42 & 1-nonene & 1.56 & 0.00 & 0.00 & 0.00 \\
\hline 14 & 2-methylpentane & 7.33 & 7.15 & 2.58 & 4.34 & 43 & n-nonane & 3.56 & 0.89 & 0.36 & 0.17 \\
\hline 15 & C5|C6 carbonyl & 0.00 & 0.00 & 0.80 & 0.22 & 44 & benzaldehyde & 0.00 & 0.00 & 0.28 & 0.55 \\
\hline 16 & C6 Carbonyl & 0.00 & 0.00 & 1.83 & 1.40 & 45 & $\alpha$-pinene & 1.20 & 0.00 & 0.00 & 0.00 \\
\hline 17 & 3-methylpantane & 5.33 & 5.86 & 5.04 & 6.39 & 46 & n-propylbenzene & 2.44 & 0.95 & 0.47 & 0.36 \\
\hline 18 & C6|C7 aldehyde & 0.00 & 0.00 & 0.00 & 1.40 & 47 & m-ethyltoluene & 2.22 & 0.00 & 0.00 & 0.00 \\
\hline 19 & 2-methyl1-pentene & 2.67 & 0.00 & 0.00 & 0.00 & 48 & p-ethyltoluene & 3.33 & 0.36 & 0.03 & 0.00 \\
\hline 20 & n-hexane & 4.67 & 2.96 & 0.87 & 0.68 & 49 & 4-methylnonane & 4.60 & 0.57 & 0.14 & 0.09 \\
\hline 21 & methylcyclopentane & 3.67 & 1.09 & 2.61 & 1.47 & 50 & C8|C11 carbonyl & 0.00 & 0.00 & 0.31 & 0.23 \\
\hline 22 & 2,3,3-trimethyl-1-butene & 4.57 & 0.00 & 0.00 & 0.00 & 51 & 1,2,4-trimethylbenzene & 12.44 & 1.35 & 0.38 & 0.23 \\
\hline 23 & benzene & 7.33 & 6.36 & 5.75 & 5.87 & 52 & n-decane & 4.00 & 0.63 & 0.11 & 0.06 \\
\hline 24 & cyclohexane & 3.33 & 1.23 & 1.13 & 0.93 & 53 & sec-butylbenzene & 1.40 & 0.62 & 0.20 & 0.09 \\
\hline 25 & 2,3-dimethylpentane & 4.86 & 2.91 & 2.64 & 0.92 & 54 & 1,3-diethylbenzene & 3.60 & 0.78 & 0.47 & 0.26 \\
\hline 26 & 3-methylhexane & 10.00 & 3.56 & 0.86 & 0.57 & 55 & acetophenone & 0.00 & 2.48 & 2.49 & 2.04 \\
\hline 27 & 2,2,4-trimethylpentane & 3.25 & 1.53 & 0.64 & 0.69 & 56 & methylbenzaldehyde & 0.00 & 4.30 & 4.62 & 3.70 \\
\hline 28 & n-heptane & 4.57 & 1.74 & 1.03 & 1.26 & 57 & 1,2,3,5-tetramethylbenzene & 1.20 & 0.70 & 0.17 & 0.06 \\
\hline 29 & aromatic carbonyl & 0.00 & 0.00 & 0.35 & 0.38 & & & & & & \\
\hline
\end{tabular}

in Fig. 3 are not included in the grouped categories, i.e., they are not counted twice.

A non-reactive dilution tracer was used to monitor losses due to dilution during each experiment (see "Dilution Tracer" in Fig. 3). The concentration data presented here, however, were not corrected for this dilution. The data were tabulated in this way to represent the chamber contents during exposure periods accurately, rather than as measures of the reactivities of the species present.

The volume of chamber air needed for the exposures and sampling led to dilution of injected initial reactants prior to sunrise (Figs. 2 and 3). Significant losses in NO and VOC concentrations began just after sunrise as a result of chemical reaction. These losses continued until a given species was consumed or the oxidant production from photolysis processes stopped (i.e., the sun set).

To illustrate the types of photochemical transformations that we typically observe, four GCMS chromatograms are shown in Fig. 5. These chromatograms show the change in the gas-phase VOC composition during the course of photochemical ageing during experiment III (performed on JN2509). Observed mixing ratio measurements and peak identities for hydrocarbon species from Fig. 5 are reported in Table 4.

The photochemical ageing of SynUrb54 created a clear temporal change in composition through the course of the day. The relative rates at which species were consumed were consistent with their kinetic rate constants (determined by the rate at which they react with photochemically-generated species such as hydroxyl radicals and $\mathrm{O}_{3}$; Atkinson, 2000). Olefinic compounds (alkenes) reacted at the greatest rate, and were completely consumed by midday (Figs. 3 and 5; Table 4). The aromatics and alkanes decayed more slowly, and almost all of these compounds were still detectable at the end of the day (Fig. 3, Table 4).

\subsection{Secondary carbonyls results}

The photochemical degradation of parent compounds led to the production of multiple generations of (oxidized) daughter compounds, with some species appearing early in the day and others appearing later (as shown in the example data in Figs. 4 and 5; Table 4). For many of these oxidized species, authentic standards were not available, or there were 


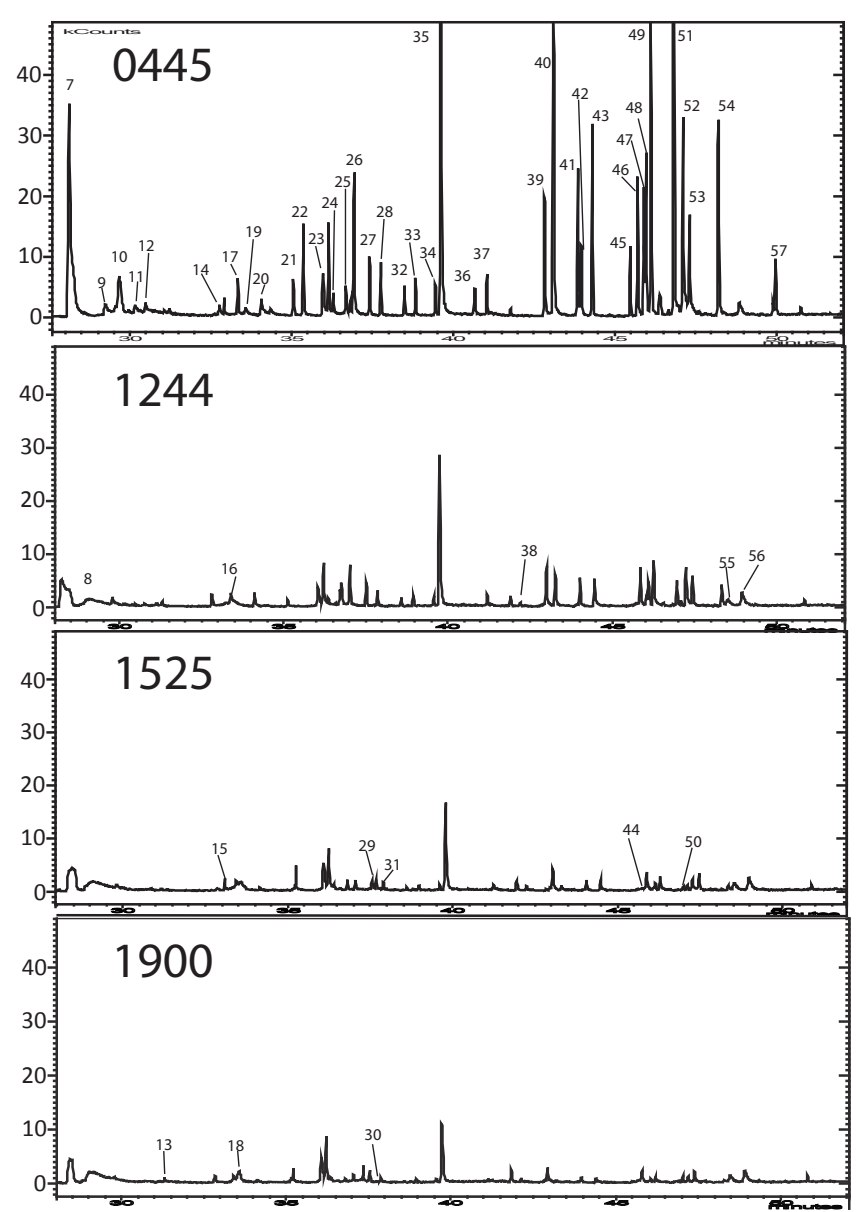

Fig. 5. FID chromatograms of VOCs during the experiment III (JN2509) using SynUrb54/NO $\mathrm{N}_{\mathrm{x}}$ mixture. Numbers labeling the species in the chromatograms correspond to the identification numbers in Table 4 and the time of sample corresponds to the red circles in Figs. 2, 3, and 4.

similarities between the mass spectra of an unknown species and more than one compound. For instances such as these (in which an unambiguous identification was not possible) daughter compounds are identified in the table as " $\mathrm{Cn}$ carbonyl" (where $\mathrm{n}$ is the carbon number of the compound). For "Cn" compounds for which more than one carbon number was possible, a "|" symbol was inserted between possible carbon numbers. Figure 4 illustrates the evolution of several generations of select daughter compounds, some of which are present at midday $(\mathrm{C} 3 \mid \mathrm{C} 4$ carbonyl, acetophenone, methylbenzaldehyde), while others do not develop until closer to sundown (C6 carbonyl, C6|C7 aldehyde). Moreover, some compounds were produced early in the day and were then consumed by further reaction (acetaldehyde, C3 carbonyl), while others persisted or continued to increase in concentration until the end of the day (acetophenone, C3|C4 carbonyl; refer to Figs. 4 and 5).

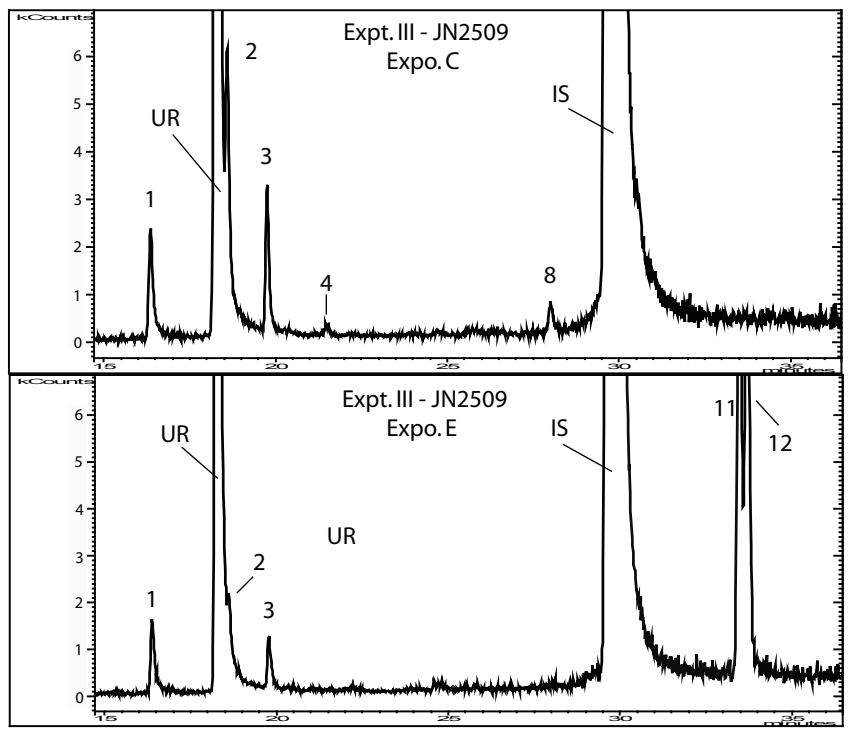

Fig. 6. GCMS selective ion chromatograms for PFBHA-derivatized samples from time windows for PFBHA sampling shown in Figs. 2, 3 , and 4 for experiment III (JN2509). Top: Exposure C; bottom: Exposure E. See Table 6 for key to numbers labeling species. The peak labeled "UR" is unreacted PFBHA reagent; the peak labeled "IS" is the internal standard.

Additional sampling using carbonyl-specific analyses (with PFBHA) that occurred over the course of the biological exposure time-windows are summarized in Table 6, and Figs. 6 and 7. It should be noted that the chromatogram at the top of Fig. 6 ideally represents the same chamber condition as the chromatogram at the top of Fig. 7 (i.e., two instances of Exposure condition C: Fresh SynUrb54 without MOA present). There were small differences in the carbonyls present in these two "Fresh" exposures. This will be discussed in more detail below.

One difference between the "Aged" samples for Expts. III and $\mathrm{V}$ is that the MOA that was added to the mixture in Expt. V was present in the PFBHA sample's air stream with the VOCs (PM was not removed from the air stream prior to sampling). What this means for our analysis is that the Expt. V chromatogram likely contains some carbonyls that were in the particulate phase. Though it is difficult to accurately measure PM collection efficiency for this sampling method, the species identified in the chromatogram (Fig. 7; Expo. F), and mixing ratios reported in Table 6, likely represent a mixture of gaseous and particle-borne carbonyls. Because current chemical sampling techniques are not able to unambiguously determine which phase detected species are in, we do not attempt to make any distinction as to whether carbonyls present in the sample were in the gas or the particle phase. The mixing ratios of the unknown carbonyls were calculated using the carbon number of the species closest to it with a positive identification in the chromatogram (2heptanone for both, Table 6). 


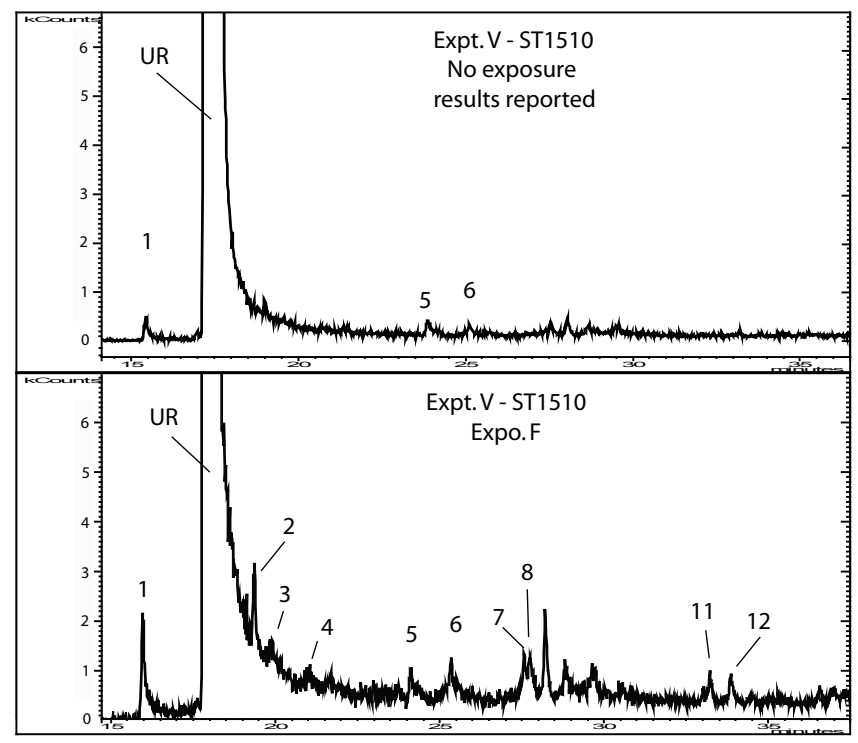

Fig. 7. GCMS chromatograms for PFBHA-derivatized samples from time windows for PFBHA sampling in experiment $\mathrm{V}$ (ST1510). Top: Exposure none; bottom: Exposure F. See Table 6 for key to numbers labeling species. The peak labeled "UR" is unreacted PFBHA reagent; the peak labeled "IS" is the internal standard.

\subsection{Particle size and mass results}

The particle mass concentrations across all of the exposures in which no particles were added were close to the limit of detection for the SMPS instrument (as determined by the average PM concentrations and $95 \%$ confidence intervals reported in Table 3). For the experiment in which SynUrb54 was photochemically aged and no MOA was added to the chamber (Expt. III), no significant secondary aerosol was formed in situ (Fig. 8; Table 3). As stated above, this agrees with previous experimental results for the photochemicalageing behaviour of this mixture. The particle mass concentrations for the exposure periods in which MOA was added to the chamber were ca. $900 \times$ to $1500 \times$ higher than the exposures without PM (Table 3). A very slight increase in the mode particle diameter was observed when MOA and SynUrb54 were mixed in the chamber (relative to MOA in clean air; from $233 \mathrm{~nm}$ to $269 \mathrm{~nm}$ for both SynUrb54/MOA mixtures; Fig. 8). The mode particle diameter increased by the same amount regardless of whether the SynUrb54 was at the "Fresh" (Expo. D) or "Aged" (Expo. F) condition (Fig. 8).

The only detectable species present in the filter samples taken during this study were components of mineral oil aerosol.

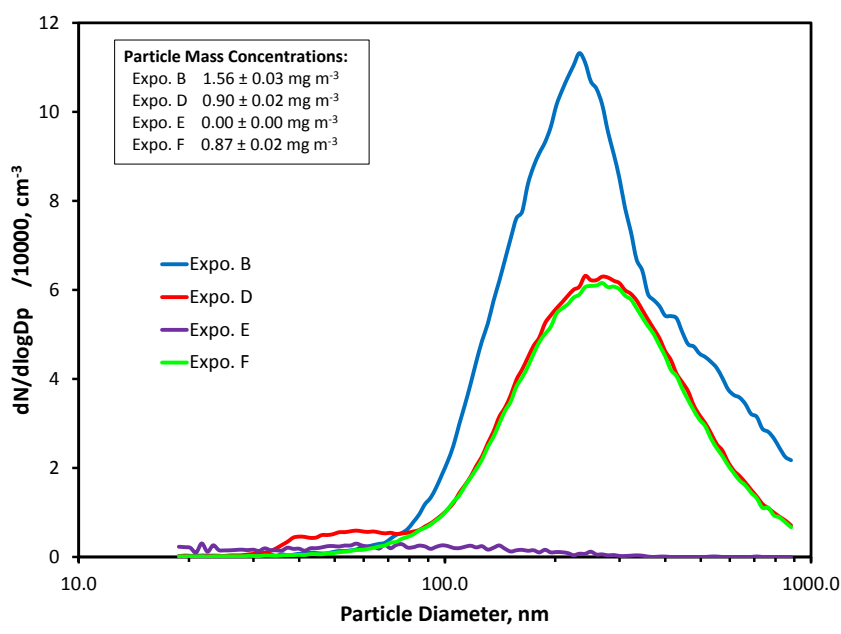

Fig. 8. Mineral Oil Aerosol (MOA) size distributions for four exposure periods: Exposure B occurred during Expt. II (AU1909), "Clean Air with MOA". Exposure D occurred during Expt. IV (ST2310), "Fresh SynUrb54 with MOA". Exposure E occurred during Expt. III (JN2509), "Aged SynUrb without MOA". Exposure F occurred during Expt. V (ST1510), "Aged SynUrb54 with MOA".

\subsection{Exposure conditions}

The experiments performed in this study resulted in exposures with the over-all gas-phase and particle concentration conditions given in Table 3 .

It is important to note that the values presented in Table 3 for VOC mixing ratios are an estimate of the total VOC in the chamber during the gas-phase exposure time-window. These estimates were calculated by correcting the initial VOC concentration $(2.00 \pm 0.04 \mathrm{ppmC})$ for dilution over time. Measured concentrations of identified VOC and carbonyl species resulting from both dilution and reaction are presented in ( $\mathrm{Ta}-$ bles 4 and 6 ).

To focus on the differences between the chamber contents during each exposure scenario, concentrations measured by direct GCMS sampling for select species were compiled in Table 5. In this table, species' identification numbers match those from Table 4 and Fig. 5. Chamber conditions match those from Table 3 and Figs. 10 and 11 (Expo. C-F). The exposure concentrations for these species vary greatly by condition, with the greatest difference between the Fresh and Aged mixtures. All of the species present in the Fresh mixtures had much lower concentrations in the Aged mixtures, to the point that some were undetectable (e.g., 2-methyl1-pentene and 2,3,3-trimethyl-1-butene). In addition, several species were only detected in the Aged mixtures (Table 5). In general, the gas-phase concentration measured for each species was lower during the experiment with the longer sunlit irradiation time (Expo. E: $14.5 \mathrm{~h}$ ) compared to the shorter sunlit irradiation time (Expo. F: $12 \mathrm{~h}$ ). These 
Table 5. Mixing ratios of select species by exposure condition. The initial ("Fresh") conditions of the two sunlit experiments (Expts. III and V) were the same, so the initial conditions of Expt. V are not reported here (for brevity). Identification numbers for each species are the same as those found in Table 4 and Fig. 5.

\begin{tabular}{|c|c|c|c|c|c|}
\hline \multirow[b]{2}{*}{ Id. } & \multirow[b]{2}{*}{ Species } & \multicolumn{4}{|c|}{$\begin{array}{l}\text { Experiment Designation, Sample Time } \\
\text { ppbV }\end{array}$} \\
\hline & & $\begin{array}{c}\text { Expt. III } \\
\text { Expo. C } \\
\text { Fresh }\end{array}$ & $\begin{array}{c}\text { Expt. IV } \\
\text { Expo. D } \\
\text { Fresh + } \\
\text { MOA }\end{array}$ & $\begin{array}{c}\text { Expt. III } \\
\text { Expo. E } \\
\text { Aged }\end{array}$ & $\begin{array}{c}\text { Expt. V } \\
\text { Expo. F } \\
\text { Aged + } \\
\text { MOA }\end{array}$ \\
\hline 3 & acetaldehyde & 0.00 & 0.00 & 0.00 & 2.49 \\
\hline 6 & $\mathrm{C} 3 \mid \mathrm{C} 4$ carbonyl & 0.00 & 0.00 & 1.30 & 0.76 \\
\hline 13 & C5 carbonyl & 0.00 & 0.00 & 0.56 & 0.34 \\
\hline 14 & 2-methylpentane & 7.33 & 4.70 & 4.34 & 3.16 \\
\hline 18 & C6|C7 aldehyde & 0.00 & 0.00 & 1.40 & 1.76 \\
\hline 19 & 2-methyl-1-pentene & 2.67 & 0.41 & 0.00 & 0.00 \\
\hline 22 & 2,3,3-trimethyl-1-butene & 4.57 & 3.02 & 0.00 & 0.00 \\
\hline 29 & aromatic carbonyl & 0.00 & 0.00 & 0.38 & 0.00 \\
\hline 30 & $\mathrm{C} 8 \mid \mathrm{C} 9$ carbonyl & 0.00 & 0.00 & 0.17 & 0.00 \\
\hline 31 & C8|C10 carbonyl & 0.00 & 0.00 & 0.77 & 0.00 \\
\hline 32 & methylcyclohexane & 1.71 & 0.97 & 0.14 & 0.00 \\
\hline 33 & 2,5-dimethylhexane & 2.75 & 2.24 & 0.37 & 0.00 \\
\hline 34 & 2,3,4-trimethylhexane & 2.22 & 0.75 & 0.32 & 0.00 \\
\hline 40 & m-xylene & 9.25 & 6.13 & 0.06 & 0.00 \\
\hline 49 & 4-methylnonane & 4.60 & 0.35 & 0.09 & 0.00 \\
\hline 50 & C8|C11 carbonyl & 0.00 & 0.00 & 0.23 & 0.00 \\
\hline 55 & acetophenone & 0.00 & 0.00 & 2.04 & 3.82 \\
\hline 56 & methylbenzaldehyde & 0.00 & 0.00 & 3.70 & 2.19 \\
\hline 57 & 1,2,3,5-tetramethylbenzene & 1.20 & 0.74 & 0.06 & 0.00 \\
\hline
\end{tabular}

Table 6. Mixing ratios for carbonyl-specific species by PFBHA-derivation and GCMS during selected experiments by exposure condition. See Table 3 for other conditions of these exposures.

\begin{tabular}{|c|c|c|c|c|c|}
\hline \multirow[b]{2}{*}{ Id. } & \multirow[b]{2}{*}{ Species } & \multicolumn{3}{|c|}{$\begin{array}{c}\text { Experiment Name, Time Window } \\
\text { ppbV }\end{array}$} & \multirow[b]{2}{*}{$\begin{array}{c}\text { Expt. V } \\
\text { Expo. F } \\
\text { Aged + } \\
\text { MOA }\end{array}$} \\
\hline & & $\begin{array}{c}\text { Expt. III } \\
\text { Expo. C } \\
\text { Fresh }\end{array}$ & $\begin{array}{c}\text { Expt. III } \\
\text { Expo. E } \\
\text { Aged }\end{array}$ & $\begin{array}{c}\text { Expt. V } \\
\text { Expo. D } \\
\text { Fresh }\end{array}$ & \\
\hline 1 & formaldehyde & 16.69 & 10.97 & 3.34 & 13.15 \\
\hline 2 & acetaldehyde & 9.10 & 0.61 & Detected & 1.63 \\
\hline 3 & acetone & 2.79 & 0.92 & - & 1.06 \\
\hline 4 & hydroxyacetaldehyde & 0.87 & - & - & 0.75 \\
\hline 5 & pentanal & - & - & 0.32 & 1.04 \\
\hline 6 & 2-hexanone & Detected & Detected & 0.27 & 3.11 \\
\hline 7 & hexanal & - & - & - & 9.11 \\
\hline 8 & 2-heptanone & 2.74 & Detected & - & 7.31 \\
\hline 9 & unknown & $0.28^{*}$ & - & - & - \\
\hline 10 & unknown & - & - & - & - \\
\hline 11 & glyoxal & - & 41.09 & - & 2.54 \\
\hline 12 & methylglyoxal & - & 27.22 & - & 1.55 \\
\hline
\end{tabular}

a see Table 2 for list of experiments and run names.

$\mathrm{b}$ data from Expt. IV is missing; data from Fresh conditions of Expt. V substituted.

* carbon number estimated from next closest identified peak in chromatogram. 
non-ideal differences in conditions will be further discussed in the Discussion section.

\subsection{Biological exposure responses results}

Figure 9 provides the "key" to the colors and shading of all the biological response plots and defines the statistical significant markers for each bar. Results are presented in Fig. 10, Fig. 11, and in Table 7.

All but one of the individual biological effects measurements exhibited high precision (i.e., low noise) and the statistics for testing differences among exposures were of high power. The exception was a likely contamination issue with the assay for the IL-8 response for the Expo. D test. These results have been replaced wherever necessary with an average of previous Fresh SynUrb54/NO $\mathrm{IL}-8$ tests, which show little response above the clean air controls. These averages are marked in figures in which they appear as Expo. D' (Figs. 10 and 12, Table 7). We determined that the assay for cellular damage (LDH) for these samples, however, was not contaminated. Therefore, the exposure in Fig. 11 represents the cellular response from cells exposed during Expt. IV, and does not have a modified label.

Because the exposure times and the relative doses are different for the gas-only system and the PM-only system, the relative results for gas-only exposures cannot be compared with the relative results for PM-only exposures. Therefore, we limit our comparisons to the biological effects observed among cells exposed within the same exposure system (EAVES and GIVES).

In addition, to facilitate the inter-comparison of responses within each endpoint measurement (i.e., IL-8 or LDH), the relative responses induced by each exposure condition are presented as relative response ratios. These ratios are represented as the response to exposure " $i$ " vs. the response to exposure " $j$ " and labelled as " $\mathrm{R}_{\mathrm{r}}[i: j]$ ".

The most important of these are:

$\mathrm{R}_{\mathrm{r}}[\mathrm{A}: \mathrm{A}]$ Expo. A - the response to Clean Air is the reference for all other bars;

$\mathrm{R}_{\mathrm{r}}[\mathrm{B}: \mathrm{A}]$ Expo. $\mathrm{B}$ to Expo. A - the relative effect of PM in Clean Air when MOA was added in absence of any VOCs (Expts. I and II, April 2008 and August 2009);

$\mathrm{R}_{\mathrm{r}}[\mathrm{C}: \mathrm{A}]$ Expo. C to Expo. A - the relative effect of "Fresh" VOC gases in absence of MOA (Expts. I and III, April 2008 and June 2009);

$R_{r}[D: A]$ Expo. D to Expo. A - the relative effect of "Fresh" VOC gases in presence of MOA (Expts. I and IV, April 2008 and September 2010);

$\mathrm{R}_{\mathrm{r}}[\mathrm{E}: \mathrm{C}]$ Expo. E to Expo. C - the effect of photochemistry on gas-phase toxicity in the absence of MOA (14.5-h sunlit day, Expt. III June 2009);
$\mathrm{R}_{\mathrm{r}}[\mathrm{F}: \mathrm{D}]$ Expo. $\mathrm{F}$ to Expo. $\mathrm{D}$ - the effect of photochemistry on gas-phase toxicity and the effect of increased gas-phase toxicity on the toxicity of added MOA following a 12h sunlit day (Expts. IV and V, both September 2010, occurred during different but temporally close experiments)

These relative response ratios are presented tabularly in Table 7 and graphically in Fig. 12.

\section{Discussion}

We begin this discussion by reviewing the experimental conditions that were designed to permit testing of the hypothesis that PM "effect modification", as initially posed by the NAS, does occur in complex urban-like oxidized VOC atmospheres. We assess the extent to which we were successful in achieving these conditions and describe any limitations and ambiguities that arise in using them for the biological exposures.

Next, we examine the pattern of biological responses relative to the test environment and explore potential causal mechanisms to the extent that our data permits us.

We then discuss sampling artefacts and finally we compare our results with others.

\subsection{Creation of control environments}

To test the null hypothesis, a set of control conditions had to first be established and characterized. As stated before, the chamber was carefully prepared to remove background contaminants that might alter the behaviours of the test atmospheres (Ebersviller et al., 2012a). Here we examine the extent to which these "clean" test conditions were achieved and discuss any issues that might limit the conclusions when using them.

Even though the Clean Air exposure with MOA had nearly twice as much MOA present as the Fresh or Aged exposures (both with MOA), neither of the in vitro systems registered an increase in toxicity from exposure (Table 3, Figs. 10 and 11). This demonstrates that MOA itself is not inherently toxic, as we reported previously (Ebersviller et al., 2012a). This was a major point that we needed to establish in support of this work, and it appears that the non-toxic properties of MOA are invariant over a wide range of PM mass concentrations. Moreover, any affect that variations in RH might have had on the cells was minimal (Ebersviller et al., 2012a), so the likelihood of RH variations causing the increase in response observed from the Aged exposures is negligible. One Clean Air exposure was performed in April (Expo. A), while the other was performed in August, a year later (Expo. B). Since no response was measured from either control exposure atmosphere, any chance that our observations were influenced by some unknown, seasonally-variable, inherent quality of the chamber itself can be discounted (Figs. 10 


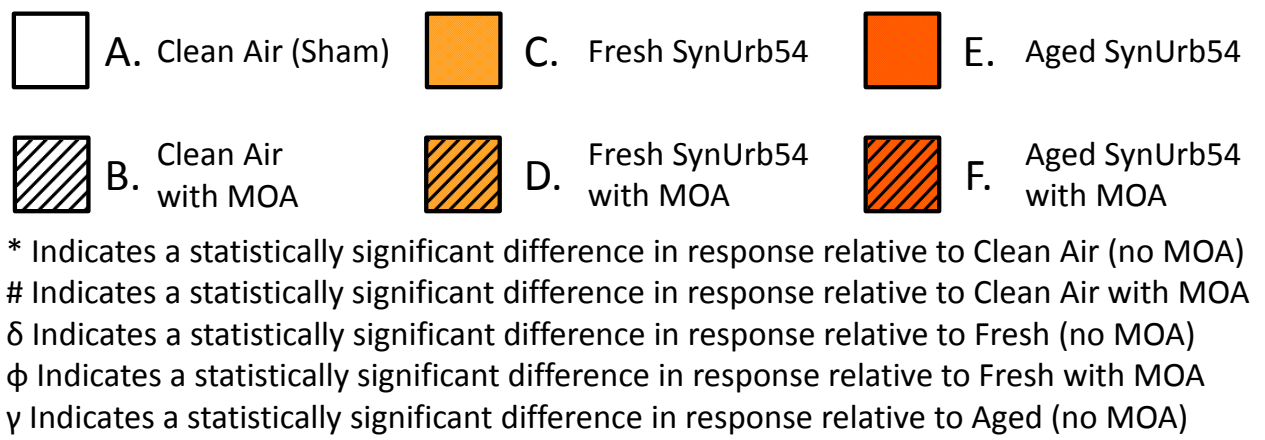

Fig. 9. Key for biological effects response plots in Figs. 10 and 11.
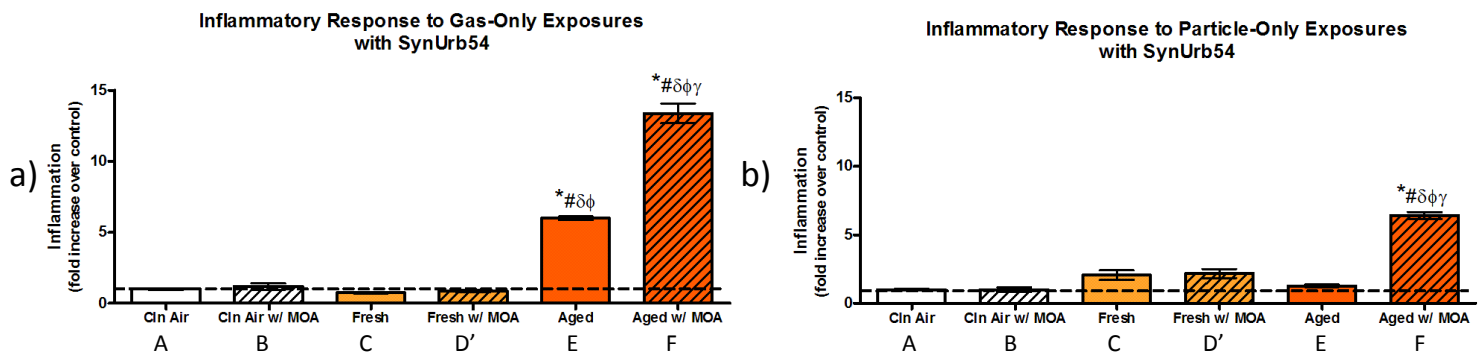

Fig. 10. The IL-8 inflammatory response of lung cells following exposure to six air mixtures. The response induced by exposure to (a) the gaseous components of each mixture and (b) the particle-phase components of each mixture.
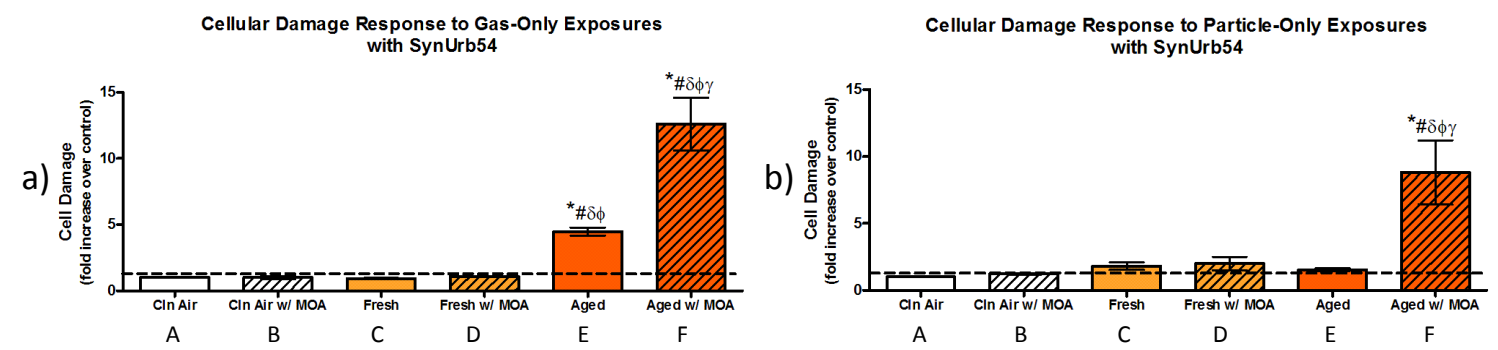

Fig. 11. The LDH Cellular damage following exposure to six air mixtures. The response induced by exposure to (a) the gaseous components of each mixture and (b) the particle-phase components of each mixture.

and 11). Therefore, with minimal criteria (Ebersviller et al., 2012a), we were successful in creating stable "clean" atmospheres in our outdoor chamber that could be used as our baseline ("zero effect" exposure).

\subsection{Creation and consistency of urban-like atmospheres}

To study the dynamic entanglements of the phases in an urban-like environment, we first needed to create airborne mixtures of VOCs that approached the complexity of the ambient urban environment. The SynUrb54 mixture has been extensively used and well studied by our research group in the past, so it was an ideal candidate for use in this study. The "Fresh" conditions in the chamber are a well designed model for the observed morning atmospheres in large urban areas.
While the average mixing ratios in some urban areas may have changed since the design of the mix, the identities of the VOCs likely have not. These conditions are a model that can be used to create a highly repeatable set of conditions more complex than has been used in other chamber work, which often use only 6 to 10 VOCs in their mixtures. When the SynUrb54 mixture is photochemically oxidized it creates hundreds to thousands of oxidized species in situ, many of which would be unavailable to researchers attempting to evaluate their toxicity in more-traditional ways. This "Aged" condition in the chamber truly begins to approach the complexity of gaseous pollutants in urban areas.

There were some small differences in composition between the two "Fresh" chamber conditions without MOA (Expo. C). Specifically, the presence of certain oxidized 
Table 7. Relative Response Ratios for gas-only and PM-only IL-8 and LDH responses to exposures, with and without added MOA.

\begin{tabular}{|c|c|c|c|c|}
\hline \multirow[b]{2}{*}{ Relative Response Ratio ${ }^{\mathrm{a}}$} & \multicolumn{2}{|c|}{$\begin{array}{l}\text { IL-8 - Irritation }{ }^{\mathrm{b}} \\
\text { Exposure Type }\end{array}$} & \multicolumn{2}{|c|}{$\begin{array}{c}\text { LDH - Cellular Damage } \\
\text { Exposure Type }\end{array}$} \\
\hline & gas-only & PM-only & gas-only & PM-only \\
\hline \multicolumn{5}{|l|}{ Clean Air } \\
\hline $\mathrm{R}_{\mathrm{r}}[\mathrm{A}: \mathrm{A}]$ & 1.0 & 1.0 & 1.0 & 1.0 \\
\hline $\mathrm{R}_{\mathrm{r}}[\mathrm{B}: \mathrm{A}] \quad \mathrm{w} / \mathrm{MOA}$ & 1.2 & 1.0 & 1.0 & 1.2 \\
\hline \multicolumn{5}{|l|}{ Fresh SynUrb54 to Clean Air } \\
\hline $\mathrm{R}_{\mathrm{r}}[\mathrm{C}: \mathrm{A}]$ & 0.7 & 2.0 & 0.9 & 1.8 \\
\hline $\mathrm{R}_{\mathrm{r}}[\mathrm{D}: \mathrm{A}]$ & $0.8^{\mathrm{c}}$ & $2.1^{\mathrm{c}}$ & 1.1 & 2.0 \\
\hline \multicolumn{5}{|c|}{ Aged SynUrb54 to Fresh SynUrb54 } \\
\hline $\mathrm{R}_{\mathrm{r}}[\mathrm{E}: \mathrm{C}]$ & 8.1 & 0.6 & 4.9 & 0.9 \\
\hline $\mathrm{R}_{\mathrm{r}}[\mathrm{F}: \mathrm{D}]$ & $15.6^{\mathrm{c}}$ & $3.0^{c}$ & 11.4 & 4.4 \\
\hline
\end{tabular}

a $\mathrm{R}_{\mathrm{r}}[i: j]$ means ratio of Expo. $i$ to Expo. $j$. Refer to Table 3 for definitions of Expo. A to $\mathrm{F}$.

${ }^{\mathrm{b}}$ Bold entries are statistically significant ratios at $p \leq 0.05$.

c Values represent comparison to $D^{\prime}$ rather than $D$-refer to text for explanation.

species in the "Fresh" condition during Expt. III (acetone and 2-heptanone; Fig. 6) is from low levels of $\mathrm{O}_{3}$ that lingered in the chamber from the day before (Fig. 2 before 02:00), which likely reacted with the components of SynUrb54 as they were injected into the chamber. This $\mathrm{O}_{3}$ was titrated with $\mathrm{NO}$, but in this instance the VOCs were added concurrently with the titration, allowing the $\mathrm{O}_{3}$ to oxidise some of the VOCs in the mix. This small introduction of oxidized species to the "Fresh" mixture was not sufficient to alter the biological effects of the chamber contents (Figs. 10-12, and Table 7).

We also observed some variability in the "Aged" condition in the chamber. In particular, there were some day-to-day differences in the identities and mixing ratios of the oxidized species present (Table 6), as well as in the $\mathrm{O}_{3}$ concentration generated by the photochemical ageing process (ca. $110 \mathrm{ppb}$, refer to Table 3). It is important to note that, while some observed VOC mixing ratios in the Aged mixtures were lower when MOA was added, others were higher. The differences in concentration cannot be assigned unambiguously to particle uptake, and may be due to a combination of factors. The presence of MOA in the chamber should, therefore, be thought of as co-incident with these variations in concentration, rather than explicitly causative. Most likely, the reason the observed mixing ratios varied from one experiment to the next had more to do with the differences in the length of the day and, by extension, the extent of reaction in the system.

The goal for these experiments was for substantial reproducibility of conditions and exposures for the VOC containing experiments. These experiments were complex and required significant preparation and analysis time. They also competed with other experiments for time in the outdoor chamber, and thus it was not possible to run the five experiments in a short time period. Unfortunately this scheduling issue confounds a "treatment change" (i.e., the presence or absence of MOA), with a "seasonal change" (i.e., length of day and its influence on the extent of gas-phase reaction creating toxicant burden). The reality of scheduling, the execution of the run, the complexity of establishing conditions, and simultaneously taking complex measurements resulted in some non-ideal results that will be discussed further below.

Some disagreement between direct measurements of the chamber by GCMS and the PFBHA-analysis method is also expected, and should not be seen as a shortcoming in our dataset. The reason that PFBHA-derivative samples are collected directly below the chamber (and not in the laboratory) is that polar compounds can be lost in sample lines. Moreover, direct analysis of carbonyl-compounds by GCMS can be unreliable, while numerous studies have used PFBHA to great effect (Ebersviller et al., 2012a; Seaman et al., 2006; Liu et al., 2005, 1999a,b; Yu et al., 1997).

The particle size distribution of each exposure atmosphere was continually monitored, so we are able to rule out the effects of particle size variation on the observed toxicological responses (refer to Fig. 8). In addition, PM was never introduced to the chamber in the presence of sunlight in any of the experiments presented here, meaning that the particles themselves were never subjected to the possibility of having their toxicity or chemical composition altered by direct reaction with the sun. Further, the PM composition is a mixture of alkanes that do not react with ozone and, in the dark, there is no source of hydroxyl radicals. Thus, any increase in the toxicity of the particle phase was most likely due to its uptake of gas-phase toxics.

Due to the dynamic nature of the equilibria between the gas and particle phases, it is not possible to absolutely 
determine the distribution of a volatile or semi-volatile species across the phases with current chemical sampling techniques. For instance, when chamber contents are sampled directly with a GCMS, PM is typically removed via an in-line filter to avoid clogging the injection system and/or column. While this may seem to remove particle-borne compounds from the analysis stream, the pressure drop across the filter is likely to lead to off-gassing of volatile species from the back side of the filter, thereby reintroducing them to the sample stream. Other filter sampling artefacts are discussed below.

We have demonstrated that we can create a highly complex, urban-like system that consists of a mixture of primary, secondary, tertiary and beyond oxidized products, even if we can not totally identify and quantify all of the components. Our systems have some daily variations that lead to differences in the observed concentrations of some products. Nevertheless, these systems remain highly representative of urban-like environments and are, therefore, useful in demonstrating the existence of PM "effect modification", even if the cause of the observed effect can not be explicitly identified. Furthermore, the totally unambiguous results of the Part 1 study show that PM effect modification occurs, and was caused by the uptake of a single VOC by the particle. In this study, even with the variations in the conditions in the chamber, all SynUrb54-type experiments made similar complex mixtures of the same types of compounds that were used in Part 1, and did not introduce enough ambiguity to the results to alter our conclusions. It is the integration of chemical and biological measurements that allows us to see that species are distributed between the phases, rather than concentrated in the gas phase and absent from the condensed phase.

\subsubsection{Biological exposures and "effect modification"}

Our results clearly show that when a non-toxic PM is added to these complex oxidized-VOC systems, like in the singlespecies VOC systems in Part 1, the PM becomes toxic to cells in the PM-only biological exposure system. This is direct proof that in situ generation of gas-phase VOCs that are toxic to cells exposed in the gas-only biological exposure system can, in the presence of non-toxic PM, modify that PM to be toxic to cells exposed in the PM-only biological exposure system. By extension to real urban atmospheres, the atmospheric oxidation of ambient primary VOCs can make otherwise non-toxic PM become toxic in the lungs of exposed humans. This is from atmospheric chemistry and physics processes phenomena that cannot be ignored when assessing the health-related consequences of the presence of PM in urban environments.

Beyond the direct demonstration shown here, atmospheric scientists would like a mechanistic explanation, or a process identified, to explain observed phenomena. As stated above, the amount of photochemical ageing that occurs in a given system is dependent upon environmental variables such as the intensity of the sunlight, atmospheric pressure, temperature, and humidity. We are able to control the humidity in the system by modifying the dew point in the chamber, as described in Part 1 (Ebersviller et al., 2012a). We "control" the remaining environmental variables for the system by performing these experiments during hot summer days with little cloud cover. The length of the day, however, can still be the determining factor for the extent to which chamber contents react. One of the sunlit experiments (Expt. III) was performed on 25 June (close to the summer solstice) and the other (Expt. IV) was performed on 15 September (close to the autumnal equinox). As a consequence, the June experiment experienced $14.5 \mathrm{~h}$ of high overhead sun before the "Aged" exposure period (Expo. E) and the September experiment experienced only $12 \mathrm{~h}$ of sunlight (with lower elevation) before the "Aged" exposure period (Expo. F). In addition, the average and peak temperatures were both higher in June than September, further accelerating the progress of the reaction in the system. The Expo. F condition (September) also had MOA added, which - based on several other test results should not enhance the gas-phase toxicity. Nevertheless, the outcome of Expo. F relative to Expo. E (which did not have MOA added), was a larger observed biological effect. It is easy to infer that this gas-phase outcome was due to the presence of MOA. Based on our chemical measurements, as well as previous research (Doyle et al., 2007), it is more likely that the increased biological response observed in Expo. $\mathrm{F}$ was due to the higher concentration of more-toxic gas-phase species in the experiment. The shorter photoactive period of the experiment performed in September likely did not have sufficient time to drive the oxidative removal of secondary toxic products from the chamber prior to exposure.

These experimental physical condition differences (e.g., less sunlight) resulted in both chemical differences (see Table 3 VOCs for Expo. E verses VOCs for Expo. F, where parent and daughter VOCs in the longer day were $20 \%$ lower) and gas-phase biological results differences (see Figs. 10a and 11a - Expo. E vs. Expo. F - where higher levels of gasphase carbonyls that remained unreacted during the shorter day are effective in generating inflammation and cell damage).

The observed increase in biological effect markers for gasonly exposures when SynUrb54 was photochemically aged was expected, as similar observations have been made previously (Sexton et al., 2004; Lichtveld et al., 2012; Doyle et al., 2007, 2004). In the gas-only exposure system, the Aged condition with added MOA resulted in ca. $2 \times$ the response observed from the Aged mixture without added MOA (Expo. E and F; Fig. 12 and Table 7). It is possible that the strong gas-phase toxicological response to the Aged exposure with MOA (Expo. F) is due to effects caused by a combination of the measured carbonyl compounds, or the measured compounds and $\mathrm{O}_{3}$ (i.e., synergism or co-pollutant effects). Based on previous findings, however, it is also possible that 

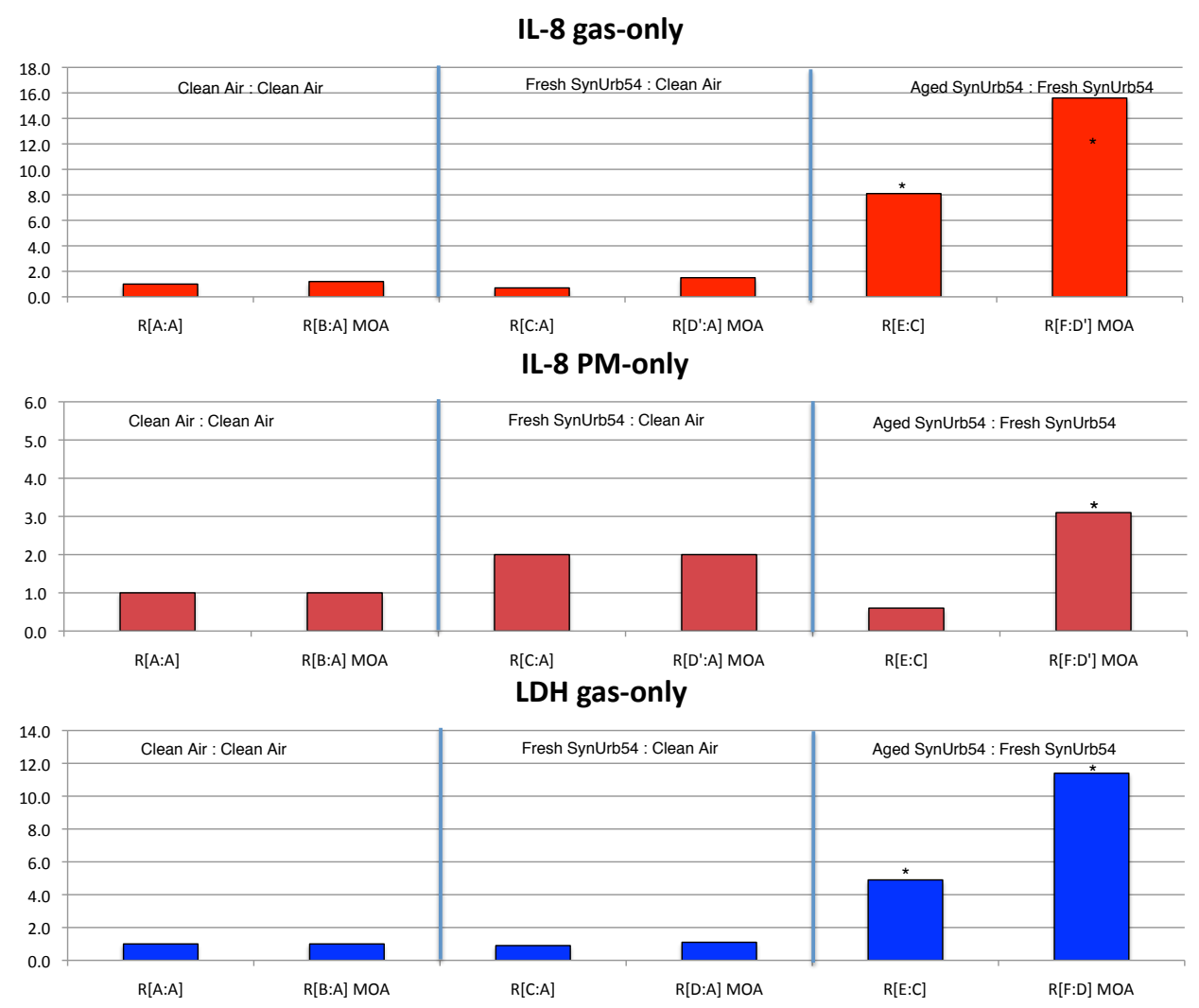

LDH PM-only

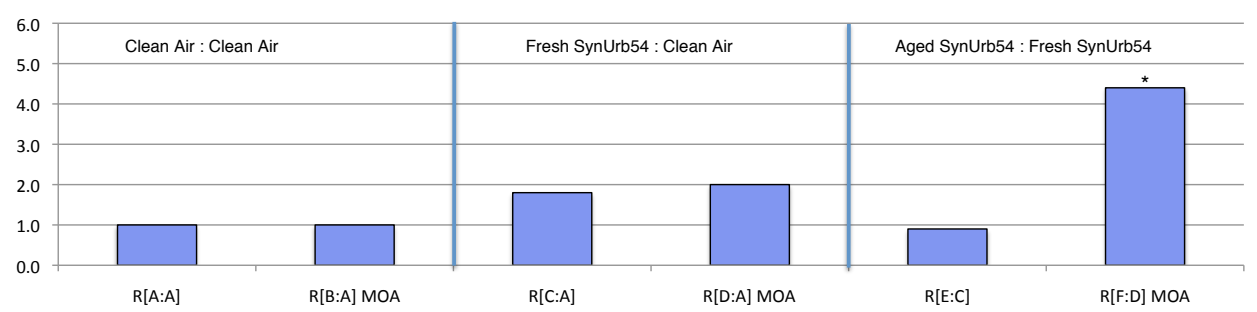

Fig. 12. Biological Relative Response Ratios by experiment type, endpoint, and exposure system. This Figure is a graphical representation of the numbers presented in Table 7 (* indicates ratio is statistically significant at $p \leq 0.5$ ).

undetected species and/or species present at a trace level contributed significantly to the observed response (Doyle et al., 2007). For this reason, we are not attempting to indicate specific causative agents in our results. Further toxicological investigation of the species detected will be necessary for their relative contributions to the total observed responses to be accurately measured. Whatever the causal relationship is eventually discovered to be, when taken in combination with the research presented in the Part 1 study in this series (Ebersviller et al., 2012a), we can conclude that gaseous air toxics partitioned to the PM are likely responsible for the observed increase in response.

Occasionally, there were slight variations between the responses observed in the biological effect markers we measured. In comparing response results from inflammation (Fig. 10) with response results from cellular damage
(Fig. 11), the reader should note that, in general, in our previous tests (with SynUrb54 reactive mixtures, as well as with the exposures in Part 1 (Ebersviller et al., 2012a)), a larger IL-8 response can occur without a matching LDH response. In addition, in testing for dose-response relationships for a single toxicant, we have found a nearly linear correlation between total carbonyl concentration in the exposure and LDH response. This same relationship was not found for IL-8, which exhibited signs of saturation. If the IL8 response (which requires living, functioning cells to create the cytokine), is "corrected" for the extent of cell death (as measured by increasing LDH), then the observed IL-8 dose-response becomes more linear (Sexton et al., 2012). Thus, our work suggests that inflammatory responses occur at lower exposure levels than do cellular damage responses. A lower response for LDH could merely indicate that, while 
the insult was sufficient to elicit an inflammatory response from the cells, it was not enough to result in failure of the cellular membrane. Conversely, if an exposure is severe enough, cells may die before they are able to produce enough IL- 8 cytokine to be detected with commercially-available assays.

As stated above, our study provides some insight, but was not designed to unravel the specific chemical causes of gasphase toxicity by itself, which may vary as chamber experimental conditions vary over seasons. Our results are, however, strongly suggestive that oxygenated compounds (especially those that have a carbonyl function) are major components in the evolution and transfer of toxicity among the phases. While not as unambiguous as we had wished, we consider these results to be, nevertheless, adequate to support the hypothesis that photochemically-produced gaseous toxicants can modify non-toxic PM so that it becomes toxic to lung cells.

\subsubsection{Discussion of sampling artefacts}

There are several possible explanations for the lack of detectable species in our filter samples. As we mentioned above, our chemical analysis concentrates largely on carbonyl-containing compounds (specifically, aldehydes and ketones). There is a long history of evidence that species in the condensed phase tend to be organic acids, large hydrocarbons (such as PAHs), and oligomers (Cao and Jang, 2008; Lee et al., 2004; Kamens and Jaoui, 2001). None of these classes of compounds would be derivatised by PFBHA, which reacts preferentially with aldehydes and ketones (Liu et al., 1999a,b; Yu et al., 1995). So, by derivatising our filter samples with PFBHA, we may simply have missed the species that were present. In future work, multiple filters will be taken at each time point, thereby allowing us to preferentially target more classes of compounds as well as doing more generalized analysis.

It has been a common practice that, to increase the likelihood of having enough material to detect with current analysis methods, researchers typically try to collect as much particulate matter as possible. In the past, sampling artefacts have been documented to alter the chemical composition of particles collected on filters (Sihabut et al., 2005; Volckens and Leith, 2003; Lichtveld et al., 2012). While these studies were mostly limited to large, low volatility compounds thought to be the mostly likely in the particle phase, it can be extrapolated that these effects would be greatly enhanced for species with higher volatilities - to the point that some species would be completely removed from the particle phase during the sampling process. So, while collecting as much material as possible might seem to increase the likelihood of detecting more species in a sample, the increased pressure drop across the filter membrane as it becomes plugged with PM may, in fact, impede the improved detection of trace species.
Moreover, to be weighed and prepared for analysis accurately, filters need to be handled multiple times after sampling. Placing particle-laden filters into clean laboratory air will also interrupt the equilibria between the PM and the species partitioned to it - causing partitioned species to leave the filter by off-gassing to the air. Researchers (ourselves included) attempt to mitigate these effects by performing analyses quickly and efficiently, but it is ultimately unlikely that the particles that are eventually analysed will have exactly the same chemical composition as those that were in the air. In addition, even though our filters were stored in a freezer at $-20^{\circ} \mathrm{C}$, prolonged filter storage prior to analysis may have contributed to the loss of species from our samples.

Any and all of these effects are possible explanations for the lack of detectable species in the filter samples from the SynUrb54 experiments. All of these concerns point toward the need for new particle methods (for both chemical analysis and toxicology) that will not interrupt the equilibria between $\mathrm{PM}$ and the species partitioned to it.

\subsection{Potential differences to traditional PM toxicity assessments}

This research would not have been possible without the in vitro exposure systems that we have available to us. Traditionally, the toxicity of PM is estimated by collecting particles and then resuspending them in a liquid medium that can be instilled onto in vitro cells or into the lungs of test animals (Steenhof et al., 2011; Tsukue et al., 2010; Weldy et al., 2011; Farina et al., 2011). Additionally, in toxicology studies, filter samples are routinely left exposed to laboratory air for extended periods of time and/or autoclaved. These sample handling practices are likely to result in the loss of volatile species from the particle phase and, by extension, most likely effects such as those we observed here. The EAVES device has proven to be a sensitive biosensor for particle-borne air toxics in this study, as well as previously (Lichtveld et al., 2012; Ebersviller et al., 2012a; de Bruijne et al., 2009). If the device (or one similar to it) could be adapted to act as a chemical analysis technique, it is possible that our perception of the interplay between gases and particles would undergo a paradigm shift similar to the conception of partitioning theory.

\subsection{Summary}

We have demonstrated that test atmospheres with urban-like complexity can be created in our chamber in situ. We also successfully performed in vitro exposures to measure the biological effects induced by each of the complex test atmospheres we generated. Due to the complexity of the dynamic interactions in our systems, we are unable to unambiguously assign observed biological effects to specific species present in the test atmospheres. This causal assignment is not necessary, however, to determine that PM "effect modification" 
occurred in our experiments. This not only establishes that the hypothesis for this study is true, it demonstrates that the findings of the Part 1 study can be extended to mixtures of gases with complexity approaching the ambient environment.

\section{Conclusions}

These results together have important ramifications across the air pollution field. Our studies have shown that gas phase air toxics can, and are likely to, increase the toxicity of airborne particulate matter by directly modifying the chemical composition of the PM. These findings can help explain the inability of laboratory-based toxicologists to replicate effects seen in near-roadway epidemiology studies, which has confounded the risk assessment field and policy makers alike. The time scale for these inter-phase dynamics is on the order of seconds. What this means in the real world is that vehicle emissions (and other PM) may not be exceptionally toxic as they enter the atmosphere but, when mixed into an aged or ageing air mass, can change dramatically in composition and biological effect by the time they drift off-road and reach the general population. Therefore, due to their ability to act as pre-concentrators and delivery mechanisms for semivolatiles and SOA compounds (and their associated toxicity), even relatively "non-toxic" PM (such as salts and minerals) should not be completely discounted from regulation.

What is clear from this work is that the evolution of toxicity with photochemical ageing and the subsequent shift of that toxicity to the PM present in the mixture is an important component to understanding the response of individuals exposed in the ambient environment. Further, this work reinforces the importance of the atmosphere itself as a significant source of toxicity in air pollution. This is true for both gas/particle interactions and the evolution of toxic species with photochemical atmospheric ageing. These findings are demonstrated for test atmospheres with the full complexity of the ambient environment in the final study in this series (Ebersviller et al., 2012b).

Acknowledgements. This research was supported in part by a grant from the National Institute of Environmental Health Sciences (P30ES010126) and in part by support from the Gillings School of Global Public Health's Gillings Innovation Laboratory Program for Research and Innovation Solutions. Publication costs were provided by the Department of Environmental Sciences and Engineering in the Gillings School of Global Public Health at the University of North Carolina at Chapel Hill.

Edited by: H. Saathoff

\section{References}

ATCC: American Type Culture Collection. Cell Biology, Designation: A549, available online at: http://www.atcc.org, 2011.

Atkinson, R.: Atmospheric chemistry of VOCs and $\mathrm{NO}_{\mathrm{x}}$, Atmos. Environ., 34, 2063-2101, 2000.

Cao, G. and Jang, M.: Secondary organic aerosol formation from toluene photooxidation under various $\mathrm{NO}_{\mathrm{x}}$ conditions and particle acidity, Atmos. Chem. Phys. Discuss., 8, 14467-14495, doi:10.5194/acpd-8-14467-2008, 2008.

de Bruijne, K., Ebersviller, S., Sexton, K. G., Lake, S., Leith, D., Goodman, R., Jetter, J., Walters, G., Doyle-Eisele, M., Woodside, R., Jeffries, H. J., and Jaspers, I.: Design and Testing of Electrostatic Aerosol In Vitro Exposure System (EAVES): An Alternative Exposure System for Particles, Inhal. Toxicol., 21, 91-101, 2009.

Donahue, N., Robinson, A., Stanier, C., and Pandis, S.: Coupled Partitioning, Dilution, and Chemical Aging of Semivolatile Organics, Environ. Sci. Technol., 40, 2635-2643, 2006.

Doyle, M., Sexton, K. G., Jeffries, H. E., Bridge, K., and Jaspers, I.: Effects of 1,3-Butadiene, Isoprene, and Their Photochemical Degradation Products on Human Lung Cells, Environ. Health Perspect., 112, 1488-1495, 2004.

Doyle, M., Sexton, K., Jeffries, H., and Jaspers, I.: Atmospheric photochemical transformations enhance 1,3-butadiene-induced inflammatory responses in human epithelial cells: The role of ozone and other photochemical degradation products, Chem. Biol. Interact., 166, 163-169, 2007.

Dreher, K.: Particulate matter physicochemistry and toxicology: in search of causality-a critical perspective, Inhal. Toxicol., 12, 4557, 2000.

Ebersviller, S., Lichtveld, K., Sexton, K. G., Zavala, J., Lin, Y.H., Jaspers, I., and Jeffries, H. E.: Gaseous VOCs rapidly modify particulate matter and its biological effects - Part 1: Simple VOCs and model PM, Atmos. Chem. Phys., 12, 12277-12292, doi:10.5194/acp-12-12277-2012, 2012a.

Ebersviller, S., Lichtveld, K., Sexton, K., Zavala, J., Lin, Y.-H., Jaspers, I., and Jeffries, H.: Gaseous VOCs rapidly modify particulate matter and its biological effects - Part 3: Petroleum diesel and biodiesel oxidations, Atmos. Chem. Phys. Discuss., in preparation, $2012 b$.

Farina, F., Sancini, G., Mantecca, P., Gallinotti, D., Camatini, M., and Palestini, P.: The acute toxic effects of particulate matter in mouse lung are related to size and season of collection, Toxicol. Lett., 202, 209-217, 2011.

Hauptmann, M., Lubin, J., Stewart, P., Hayes, R. B., and Blair, A.: Mortality from solid cancers among workers in formaldehyde industries, Am. J. Epidemiol., 159, 1117-1130, 2004.

$\mathrm{Hu}$, D. and Kamens, R.: Evaluation of the UNC toluene-SOA mechanism with respect to other chamber studies and key model parameters, Atmos. Environ., 41, 6465-6477, 2007.

Jaspers, I., Flescher, E., and Chen, L.: Ozone-induced IL-8 expression and transcription factor binding in respiratory epithelial cells, Am. J. Physiol. Lung Cell Mol. Physiol., 272, L504-L511, 1997.

Jeffries, H.: Composition, Chemistry, and Climate of the Atmosphere, chap. Photochemical air pollution, 308-348, Van Nostrand Reinhold, 1995.

Jeffries, H., Sexton, K., Kamens, R., and Holleman, M.: Outdoor Smog Chamber Experiments: Reactivity of Methanol Exhaust, 
Environmental Protection Agency, Office of Mobile Sources, Ann Arbor, MI, USA, 1985.

Johnson, G., Nancarrow, P. C., Quintanar, A., and Azzi, M.: Smog Chamber Data for Testing Chemical Mechanisms at Low VOC to $\mathrm{NO}_{\mathrm{x}}$ Ratio Conditions, Final Report to EPA Cooperative Agreement, Tech. Rep. CR-821420, US Environmental Protection Agency, Office of Research and Development, 1997.

Kamens, R. and Jaoui, M.: Modeling Aerosol Formation from apinene $+\mathrm{NO}_{\mathrm{x}}$ in the Presence of Natural Sunlight Using Gas Phase Kinetics and Gas-particle Partitioning Theory, Environ. Sci. Technol., 35, 1394-1405, 2001.

Kamens, R., Jeffries, H., Gery, M., Wiener, R., Sexton, K., and Howe, G.: The Impact of a-pinene on Urban Smog Formation: An Outdoor Chamber Study, Atmos. Environ., 15, 969-981, 1981.

Lee, S., Jang, M., and Kamens, R.: SOA formation from the photooxidation of a-pinene in the presence of freshly emitted diesel soot exhaust, Atmos. Environ., 38, 2597-2605, 2004.

Lichtveld, K., Ebersviller, S., Sexton, K. G., Vizuete, W., Jaspers, I., and Jeffries, H. J.: In Vitro Exposures in Diesel Exhaust Atmospheres: Resuspension of PM from Filters versus Direct Deposition of PM from Air, Environ. Sci. Technol., 46, 9062-9070, 2012.

Lieber, M., Smith, B., Szakal, A., Nelson-Rees, W., and Todaro, G.: A continuous tumor-cell line from a human lung carcinoma with properties of Type II alveolar epithelial cells, Int. J. Cancer, 17, 62-70, 1976.

Liu, X., Jeffries, H., and Sexton, K.: Hydroxyl radical and ozone initiated photochemical reaction of 1,3-butadiene, Atmos. Environ., 33, 3005-3022, 1999a.

Liu, X., Jeffries, H., and Sexton, K.: Atmospheric photochmical degradation of 1,4-unsaturated dicarbonyls, Environ. Sci. Technol., 33, 4212-4220, 1999b.

Liu, X., Lovell, M., and Lynn, B.: Development of a Method for Quantification of Acrolein-Deoxyguanosine Adducts in DNA Using Isotope Dilution-Capillary LC/MS/MS and Its Application to Human Brain Tissue, Analyt. Chem., 77, 5982-5989, 2005.

NAS: National Research Council Research Priorities for Airborne Particulate Matter, vol. IV Continuing Research Progress, National Academies Press, Washington, DC, USA, 98-102, 2004.

Pankow, J., Liang, C., Odum, J., and Seinfeld, J.: Gas/Particle Partitioning of Semivolatile Organic Compounds to Model Inorganic, Organic, and Ambient Smog Aerosols, Environ. Sci. Technol., 31, 3086-3092, 1997.

Schlesinger, R., Kaunzli, N., Hidy, G., Gotschi, T., and Jerrett, M.: The health relevence of ambient particulate matter characteristics: coherence of toxicological and epidemiological inferences, Inhal. Toxicol., 18, 95-125, 2006.

Seaman, V., Charles, J., and Cahill, T.: A Sensitive Method for the Quantification of Acrolein and Other Volatile Carbonyls in Ambient Air, Analyt. Chem., 78, 2405-2412, 2006.
Seila, R. L., Lonneman, W. A., and Meeks, S. A.: Determination of C2 to C12 ambient air hydrocarbons in 39 U.S. cities from 1984 through 1986, Tech. Rep. EPA/600/3-89/056, US Environmental Protection Agency, Office of Research and Development, Atmospheric Research and Exposure Assessment Laboratory, 1989.

Sexton, K. G., Jeffries, H. J., Jang, M., Kamens, R. M., Doyle, M., Voicu, I., and Jaspers, I.: Photochemical products in urban mixtures enhance inflammatory responses in lung cells, Inhal. Toxicol., 16, 107-114, 2004.

Sexton, K. G., Lin, Y.-H., Lichtveld, K., Ebersviller, S., Vizuete, W., and Jaspers, I.: Dynamic gaseous air pollutant generation systems for toxicity studies using cultured cells, Inhal. Toxicol., in preparation, 2012.

Sihabut, T., Ray, J., Northcross, A., and McDow, S.: Sampling artifact estimates for alkanes, hopanes, and aliphatic carboxylic acids, Atmos. Environ., 39, 6945-6956, 2005.

Simonaitis, R., Meagher, J. F., and Bailey, E. M.: Evaluation of the condensed carbon bond (CB-IV) mechanism against smog chamber data at low VOC and $\mathrm{NO}_{\mathrm{x}}$ concentrations, Atmos. Environ., 31, 27-43, 1997.

Steenhof, M., Gosens, I., Strak, M., Godri, K. J., Hoek, G., Cassee, F. R., Mudway, I. S., Kelly, F. J., Harrison, R. M., Lebret, E., Brunekreef, B., Janssen, N. A., and Pieters, R. H.: In vitro toxicity of particulate matter (PM) collected at different sites in the Netherlands is associated with PM composition, size fraction and oxidative potential - the RAPTES project, Part Fibre Toxicol., 8, $1-15,2011$.

Takigawa, T., Wang, B.-L., Sakano, N., Wang, D.-H., Ogino, K., and Kishi, R.: A longitudinal study of environmental risk factors for subjective symptoms associated with sick building syndrome in new dwellings, Sci. Total Environ., 407, 5223-5228, 2009.

Tsukue, N., Okumura, H., Ito, T., Sugiyama, G., and Nakajima, T.: Toxicological evaluation of diesel emissions on A549 cells, Toxicol. In Vitro, 24, 363-369, 2010.

Volckens, J. and Leith, D.: Effects of Sampling Bias on Gas-Particle Partitioning of Semivolatile Compounds, Atmos. Environ., 37, 3385-3393, 2003

Weldy, C. S., Wilkerson, H. W., Larson, T. V., Stewart, J. A., and Kavanagh, T. J.: Diesel particulate exposed macrophages alter endothelial cell expression of eNOS, iNOS, MCP1, and glutathione synthesis genes, Toxicol. In Vitro, 25, 2064-2073, 2011.

WHO: Air Quality Guidelines for Europe, European Series, WHO Regional Publications, Copenhagen, Denmark, 2nd edn., 2000.

Yu, J., Jeffries, H. E., and Le Lacheur, R.: Identifying Airborne Carbonyl Compounds in Isoprene Atmospheric Photooxidation Products by Their PFBHA Oximes Using Gas Chromatography/Ion Trap Mass Spectrometry, Environ. Sci. Technol., 29, 1923-1932, 1995.

Yu, J., Jeffries, H., and Sexton, K. G.: Atmospheric photo oxidation of alkylbenzenes - I. Carbonyl product analyses, Atmos. Environ., 31, 2261-2280, 1997.

Zhang, J. and Smith, K.: Indoor air pollution: a global health concern, Br. Med. Bull., 68, 209-225, 2003. 